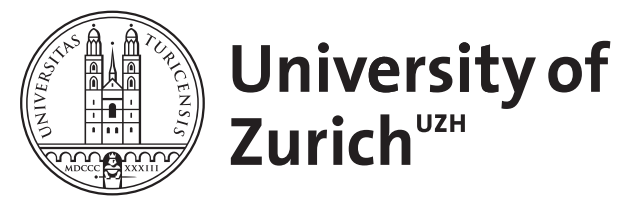

\title{
Ramsey tax cycles
}

\author{
Hagedorn, Marcus
}

\begin{abstract}
This paper asks whether tax cycles or tax smoothing represents the optimal policy in models without any extrinsic uncertainty. To answer this question, I develop a general framework for studying tax cycles in a large class of models that feature various types of frictions. This framework adds various wedges, resembling tax wedges, to the labour market, to the product market, and to money acquisition into an otherwise frictionless economy, so that it nests a large class of models used for policy analysis. I derive a criterion for this general framework that indicates when cycles are welfare-improving in a frictionless economy, and why frictions make cycles more likely to be optimal. I then calibrate two models with frictions, a labour search model and a monetary model, and show that cycles are welfare-improving under standard preferences
\end{abstract}

DOI: https://doi.org/10.1111/j.1467-937x.2009.00592.x

Posted at the Zurich Open Repository and Archive, University of Zurich ZORA URL: https://doi.org/10.5167/uzh-154307

Journal Article

Published Version

Originally published at:

Hagedorn, Marcus (2010). Ramsey tax cycles. Review of Economic Studies, 77(3):1042-1071.

DOI: https://doi.org/10.1111/j.1467-937x.2009.00592.x 


\title{
Ramsey Tax Cycles
}

\author{
MARCUS HAGEDORN
}

University of Zurich

First version received February 2006; final version accepted August 2009 (Eds.)

\begin{abstract}
This paper asks whether tax cycles or tax smoothing represents the optimal policy in models without any extrinsic uncertainty. To answer this question, I develop a general framework for studying tax cycles in a large class of models that feature various types of frictions. This framework adds various wedges, resembling tax wedges, to the labour market, to the product market, and to money acquisition into an otherwise frictionless economy, so that it nests a large class of models used for policy analysis. I derive a criterion for this general framework that indicates when cycles are welfare-improving in a frictionless economy, and why frictions make cycles more likely to be optimal. I then calibrate two models with frictions, a labour search model and a monetary model, and show that cycles are welfare-improving under standard preferences.
\end{abstract}

\section{INTRODUCTION}

In a seminal paper, Barro (1979) suggests that tax smoothing is the optimal policy if distortionary taxes are the sole option. In this paper I show that this is not always the case. Instead, some time variation in levying taxes can improve welfare, both in Walrasian settings and in models with frictions. I also demonstrate that frictions that are regarded as important in many macroeconomic models enlarge the set of parameter values-encompassing values that are considered standard-for which tax cycles lead to higher welfare.

There is a simple explanation for the optimality of tax cycles in a model with no extrinsic uncertainty. The Ramsey planner takes into account that a change in tax rates changes the price of consumption and thus interest rates. The consumption Euler equation implies that a tax cut today, financed through more debt and repaid next period, lowers the interest rate. A cycle is optimal whenever this drop in interest rates relaxes the government's budget sufficiently to compensate for the welfare loss from the induced variation in consumption and hours. Technically, the reason is the potential non-convexity of the Ramsey optimization problem. First-order conditions are then not sufficient to characterize the optimum: the firstorder approach is invalid and a cycle improves welfare.

To study the optimality of tax cycles I develop a general framework that allows for various wedges in a frictionless prototype economy and nests a large class of models. The wedges distort agents' decisions in the labour market and the product market, and their decisions to acquire money. In this framework, I develop a general condition, applicable to Walrasian settings and to models with frictions, that indicates when a tax cycle generates higher welfare than tax smoothing does. This criterion can be expressed in terms of the primitives that characterize the economy-preferences, the size of the government and the wedges-which emphasizes the role of frictions in generating optimal tax cycles.

I then apply this framework to various economies that are nested in the general framework and that provide interesting applications of the general principle. First I consider Walrasian settings, nested in the general framework, when all frictions are shut down. These frictionless 
economies serve as an overall benchmark for analysing the role of frictions. They also isolate the role of preferences in generating optimal cycles. I show that two classes of preferences exist, with different implications. One class implies that tax smoothing is optimal, whereas within the other class, tax cycles improve welfare. With separability between consumption and leisure, these two classes can be characterized fully and sharply. Under (weakly) increasing relative risk aversion (IRRA) in consumption ${ }^{1}$ tax smoothing is optimal, whereas under sufficiently strongly decreasing relative risk aversion (DRRA) tax cycles become optimal. Interestingly, DRRA is found to be the empirically relevant specification (for example, Ogaki and Zhang, 2001). ${ }^{2}$

Next I study whether frictions of various types in the labour market and in money acquisition, which are incorporated in many models, increase or decrease the range of preferences leading to optimal tax cycles. To answer this question, I make use of the various model economies with frictions nested in my framework. The theoretical results allow me to introduce the frictions one at a time in order to study these in isolation. For each of the frictions I theoretically characterize when a cycle improves welfare. Using calibrated examples I show that tax cycles are optimal under standard preferences.

As an example of labour market frictions, I consider optimal taxation in the Pissarides (1985, 2000) search and matching model. ${ }^{3}$ A non-trivial wedge arises because of search frictions that require firms to post vacancies to create employment, and wages to be formed through bargaining. When the model is calibrated in a standard way, I find that cycles become optimal for constant relative risk aversion (CRRA). As an example of frictions in money acquisition, I consider the Lagos and Wright (2005) model. A non-trivial wedge arises also in this model, since money is used in a product market with search frictions and the price of these transactions depends on the trading volume. In a parameterized example I find that cycles can improve welfare for CRRA preferences regardless of the coefficient of relative risk aversion.

Exactly the same wedges characterizing these simple models are present also in much richer models used for policy analysis. The possibility of tax cycles being optimal in these more complete models cannot be ruled out a priori and the belief that restricting oneself to IRRA or even CRRA could rule out tax cycles is not warranted. Cycles can improve welfare even in a simple model, one that is not very different from a Walrasian world. ${ }^{4}$

Further, I can partially characterize the shape of the optimal policy. An optimal policy (after the initial period) can be implemented by at most two different tax rates. The optimal policy is either constant or discontinuous. In particular, it is not necessarily differentiable as Chamley (1986) assumes in order to verify that cycles are not optimal. The welfare gains from implementing such a cycle can be substantial. They are, in terms of consumption equivalents, about $0.5 \%$ in the search and matching economy, equal to about $4 \%$ in the Lagos

1. What matters here is the elasticity of intertemporal substitution, although the preferences (DRRA, CRRA, IRRA) are classified according to their risk aversion.

2. Ogaki and Zhang (2001) reject CRRA and favour DRRA, although no consensus on the magnitude of DRRA has yet been reached. Furthermore, Vissing-Jorgenson (2002) provides evidence that richer households have a higher elasticity of intertemporal substitution than do poorer ones. For this type of preferences, this implies that risk aversion decreases with wealth. See Gollier (2001) for a further discussion of DRRA and references to the literature.

3. Following the Ramsey approach, the government issues bonds and levies a linear labour tax rate. For a different approach to taxation in a search and matching model based on informational frictions (following Mirrlees, 1971) see Hungerbühler et al. (2006).

4. Hassler et al. (2008) show that optimal capital income tax rates oscillate in a model without geometric depreciation of capital. However, their paper differs from mine in that they do not consider labour taxes, that the reason for oscillations of capital income tax rates are different, and that oscillations generically die out. 
and Wright (2005) model, and can be arbitrarily large in the frictionless case with DRRA preferences.

The remainder of this paper is organized as follows. In the next section, I present a simple model that provides the intuition and formalizes the role of frictions. Section 3 describes the general framework for analysing optimal taxation in models with and without frictions, and Section 4 considers the optimal policy in this framework. Section 5 applies these general results to a frictionless economy and Section 6 analyses models with frictions. Section 7 concludes by summarizing the results. All proofs are delegated to the Appendix.

\section{A SIMPLE EXAMPLE}

To formalize the intuition from the introduction, I now present a simple, two-period model of the labour market. The simple model illustrates which properties of frictions make tax cycles a welfare-improving policy.

Each period, vacancies $h$ are posted at a resource cost $\kappa$ to create employment $x=m(h)=$ $\frac{h^{0.5}}{10}$, which is used to produce $c=x-\kappa h$ consumption goods. All workers are unemployed at the beginning of each period. The measure one of households values consumption according to the utility function

$$
\frac{c_{1}^{1-\sigma}-1}{1-\sigma}+\frac{c_{2}^{1-\sigma}-1}{1-\sigma},
$$

where $\sigma>0$. Concerning the market structure, I consider two scenarios. One has competitive markets with Walrasian pricing; the other is characterized by search frictions. In the first scenario, $m$ is a technology to create output $x_{t}$, which is traded in a competitive market at a price $w_{t}^{C}$. In the second scenario, search frictions make filling a job costly. Once a firm pays the cost for a vacancy and meets a worker, the wage $w_{t}^{S}$ is determined through bargaining. The government can issue bonds $B_{1}$ in period 1 with a gross return $R_{1}$ and it can levy a tax $\tau_{t}$ so that the after-tax price equals $\left(1-\tau_{t}\right) w_{t}^{i}, i \in\{C, S\}$. Government expenditures are zero.

In the economy with search frictions, not all vacancies are matched with unemployed workers. Another key feature of the search economy is that the worker's threat point (or outside option) $b$ is strictly lower than the worker's after-tax productivity $1-\tau_{t}$. For matched worker-firm pairs it is thus in their mutual interest to produce and to agree on a wage which lies in the interval $\left[b, 1-\tau_{t}\right]$. Bargaining between the worker and the firm determines a wage from within this interval, which as in Hall and Milgrom (2008) equals ${ }^{5}$

$$
w_{t}^{S}=\frac{1}{2}\left(1+\frac{b}{1-\tau_{t}}\right) .
$$

Firms make profits $1-w_{t}^{S}=\frac{1}{2}\left(1-\frac{b}{1-\tau_{t}}\right)$ and they anticipate the outcome of bargaining when they post vacancies. The number of meetings between firms and workers equals $m$ so that each vacancy is filled with probability $\frac{m}{h}$. Free entry of firms implies that expected profits of firms equal zero:

$$
\kappa h_{t}=m\left(h_{t}\right) \frac{1}{2}\left(1-\frac{b}{1-\tau_{t}}\right) .
$$

5. The net wage equals $w_{t}^{S}\left(1-\tau_{t}\right)=\frac{1}{2}\left(1-\tau_{t}+b\right)$. 


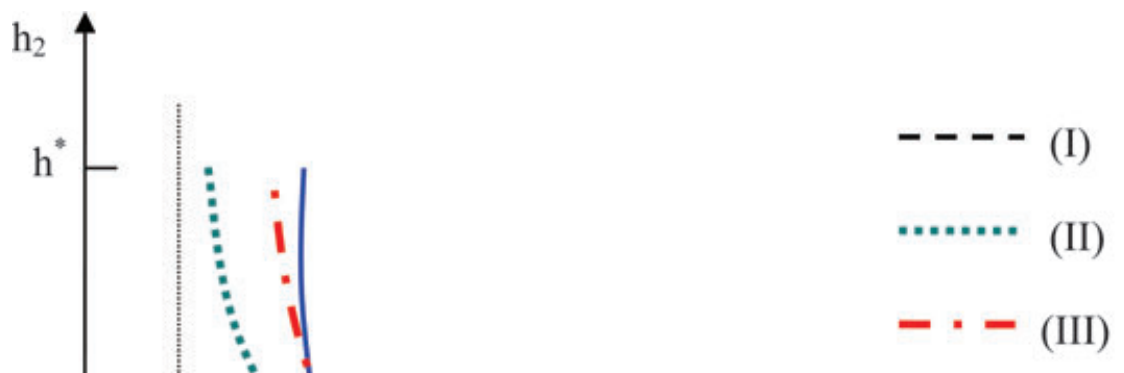

Welfare-improving Allocation

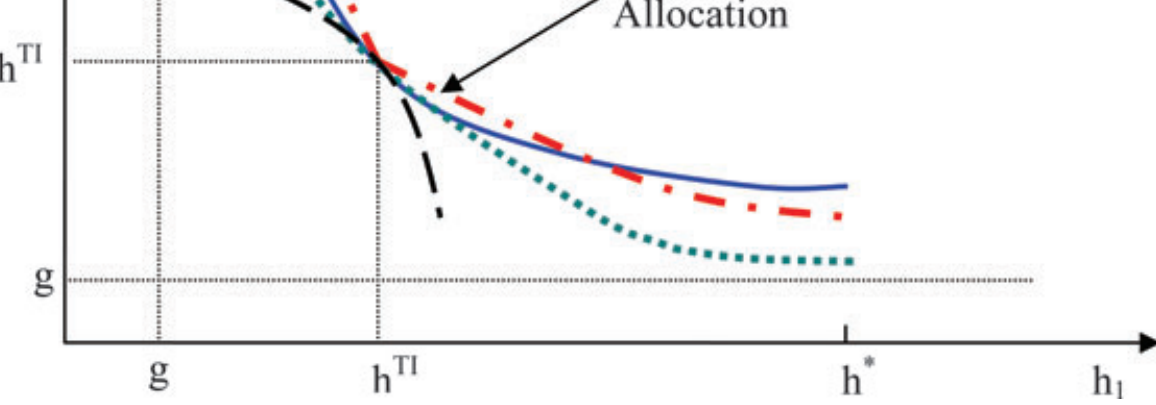

FIGURE 1

Optimal taxation with two periods

The government's intertemporal budget constraint expressed in terms of allocations, taking the consumption Euler equation $R_{1}=\frac{c_{2}^{\sigma}}{c_{1}^{\sigma}}$ and the resource constraint into account, reads

$$
\underbrace{\left(m\left(h_{1}\right)-\kappa h_{1}\right)^{-\sigma} \Omega_{1}}_{C S\left(h_{1}\right):=}+\underbrace{\left(m\left(h_{2}\right)-\kappa h_{2}\right)^{-\sigma} \Omega_{2}}_{C S\left(h_{2}\right):=}=0,
$$

where $\Omega:=(m(h)-\kappa h)\left(1-\frac{b m(h)}{m(h)-2 \kappa h}\right)$ is instantaneous tax revenue. ${ }^{6}$

The question now is whether a welfare-maximizing government chooses the same tax rate $\tau^{T I}=0$ in both periods or whether time-variation in tax rates improves welfare. The equilibrium conditions-the free entry condition and the resource constraint-imply that choosing $\tau$ is equivalent to choosing $h$. In particular, time variation in $\tau$ is optimal if and only if time variation in $h$ is optimal.

Figure 1 graphically illustrates the conditions that can render time variation optimal. Firstperiod vacancies $h_{1}$ are on the $x$-axis and second-period vacancies $h_{2}$ on the $y$-axis. The efficient level of vacancies is denoted $h^{*}$. The solid line is the indifference curve of the representative household through the point $\left(h^{T I}, h^{T I}\right)$. Allocations with more vacancies $h$ generate higher utility as long as $h$ is smaller than $h^{*}$. The graph also shows curves in the $\left(h_{1}, h_{2}\right)$ space which generate the same tax revenue as $\left(h^{T I}, h^{T I}\right)$. There are three possibilities for the shape of this curve. In Case $(I)$ the curve is concave. In Case (II) the curve is convex but "less $m-\kappa h$.

6. Solving the free entry condition for the tax rate gives $\tau=1-\frac{b m}{m-2 \kappa h}$ and thus $w^{S} m=\frac{1}{2}\left(1+\frac{m-2 \kappa h}{m}\right) m=$ 

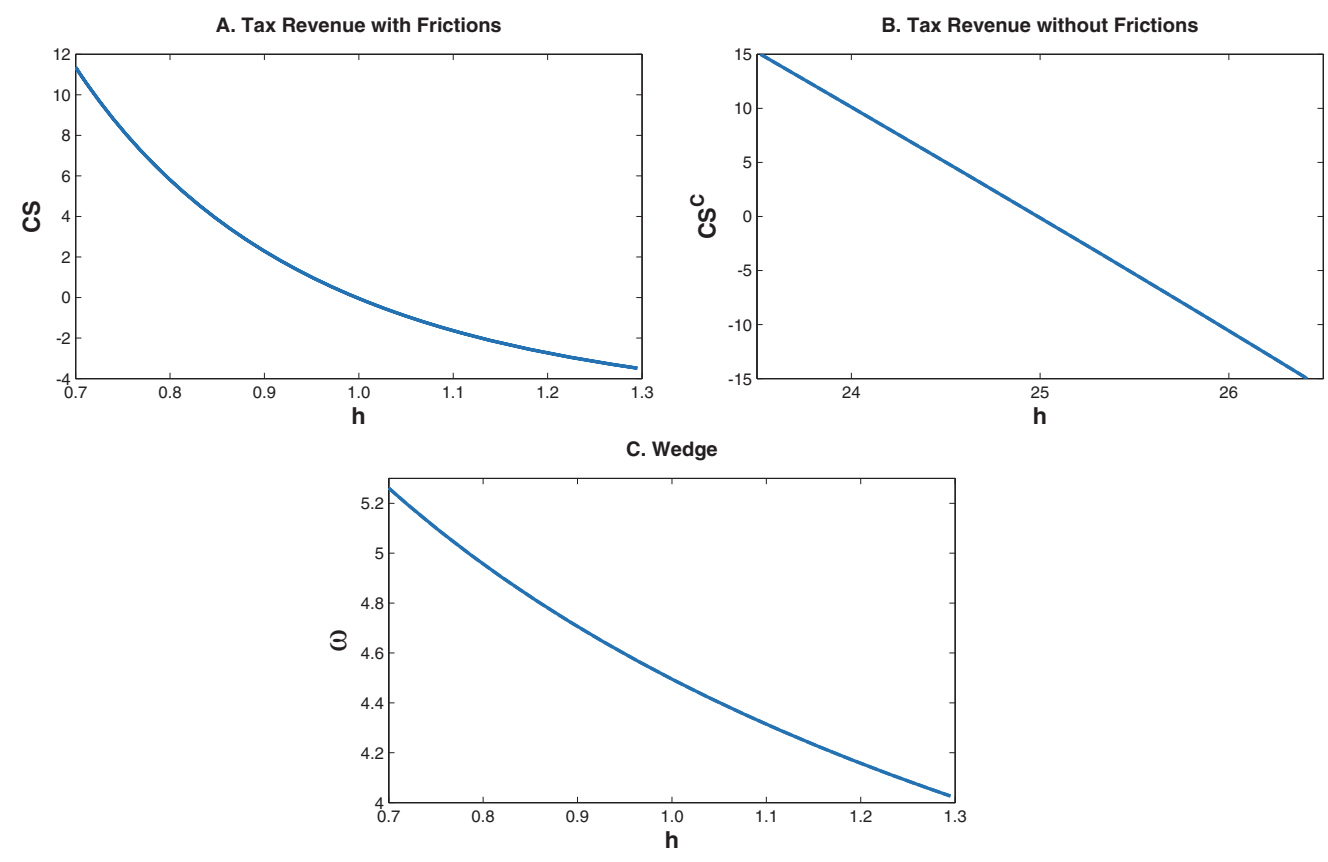

FIGURE 2

The role of frictions

convex" than the indifference curve. In Case (III) the curve is convex and "more convex" than the indifference curve at $\left(h^{T I}, h^{T I}\right)$. In the first two cases it is optimal to choose $h^{T I}$ in both periods. No combination of $h_{1}$ and $h_{2}$ generates the same tax revenue as $\left(h^{T I}, h^{T I}\right)$ and at the same time higher utility. In contrast, in Case (III), such a combination exists as the arrow identifies an allocation, which is located above the indifference curve but below the tax revenue curve.

As is evident from the graphical representation, Case (III) is possible only if tax revenue is sufficiently convex. I now explain why Case (III) describes the tax problem in the search economy whereas only Cases $(I)$ and (II) are possible in the scenario with Walrasian pricing.

For parameter values $\sigma=5, b=0.8$, and $\kappa=0.01$, panel A of Figure 2 shows period $t^{\prime} s$ tax revenue $C S$ as a function of $h$, around the constant value $h^{T I}=1$ which balances the government's budget. The function is convex, which implies that a tax cycle is implementable: increasing $h_{1}$ (through decreasing taxes and issuing debt) and decreasing $h_{2}$ (due to higher taxes) to balance the budget generate an average higher value of vacancies, $h_{1}+h_{2}>2 h^{T I}$. This is possible since such a cycle lowers the interest rate that the government has to pay on the debt issued in period $1\left(u^{\prime}\left(c_{1}\right)\right.$ decreases, $u^{\prime}\left(c_{2}\right)$ increases $)$.

More formally, consider a second-order approximation to $C S$ around $h^{T I}$ :

$$
C S(h)=C S\left(h^{T I}\right)+C S^{\prime}\left(h^{T I}\right)\left(h-h^{T I}\right)+C S^{\prime \prime}\left(h^{T I}\right)\left(h-h^{T I}\right)^{2} .
$$

A balanced budget then requires that $h_{1}$ and $h_{2}$ satisfy

$$
\left(h_{1}+h_{2}-2 h^{T I}\right)+\frac{C S^{\prime \prime}\left(h^{T I}\right)}{C S^{\prime}\left(h^{T I}\right)}\left(\left(h_{1}-h^{T I}\right)^{2}+\left(h_{2}-h^{T I}\right)^{2}\right)=0 .
$$

Equation (6) implies that convexity of $C S$ is a necessary condition for average vacancies to increase since $C S^{\prime}<0$. The size of the difference $h_{1}+h_{2}-2 h^{T I}$ depends on the first- and 
second-order derivatives of CS. A higher degree of convexity ( $C S^{\prime \prime}$ larger) makes a cycle more likely, as suggested by the graphical analysis. A flatter tax revenue function $\left(\left|C S^{\prime}\right|\right.$ smaller) also increases the average level of $h_{1}+h_{2}$, as large changes in $h$ lead to small revenue losses.

Once we establish that a cycle is feasible, we also want to know whether it increases welfare. The benefit of a cycle is that employment increases; the loss is that it leads to higher consumption volatility. In the parameterized economy, the increase in employment indeed is sufficiently large to outweigh the losses. Increasing $h_{1}$ by $10 \%$ makes it necessary to decrease $h_{2}=0.93$, which leads to consumption levels $c_{1}=0.094$ and $c_{2}=0.087\left(c^{T I}=\right.$ $\left.m\left(h^{T I}\right)-\kappa h^{T I}=0.09\right)$ and to a welfare gain expressed in consumption equivalents of $0.15 \%$. The optimal policy leads to even larger welfare gains of $8.1 \%$, as it implements $h_{1}=7.42$ and $h_{2}=0.82$.

To understand the role of frictions, consider now the corresponding model with Walrasian pricing. In this scenario, output is traded at a price $w^{C}=1$, and vacancies are chosen to maximize $(1-\tau) w^{C} m(h)-\kappa h$, which results in the after-tax price $(1-\tau) w^{C}=(1-\tau)=$ $\frac{2 \kappa h}{m(h)}$ and thus

$$
C S^{C}\left(h_{t}\right)=\left(m\left(h_{t}\right)-\kappa h_{t}\right)^{-\sigma}\left(m\left(h_{t}\right)-2 \kappa h_{t}\right),
$$

where instantaneous tax revenue $\Omega^{C}=\tau w^{C} m(h)=\frac{m(h)-2 \kappa h}{m(h)} m(h)=m(h)-2 \kappa h$.

With Walrasian pricing, finding out whether a cycle can improve upon a constant allocation is simple. The first welfare theorem implies that a cycle is not optimal, as it applies to the Walrasian market setting but not to the search economy. Nevertheless, it is instructive to look at the shape of $C S^{C}$. Plotting $C S^{C}$ around the efficient $v^{C, *}=25$ (panel B of Figure 2) establishes that this function is not convex as it is for the search economy, so that a cycle does not increase the average number of vacancies, a prerequisite for a cycle to improve welfare. The function $C S^{C}$, however, is convex at lower values of $h$, but the economy is located on the "wrong side" of the Laffer curve in this case ( $C S^{C}$ is upward sloping). In particular, $C S^{C}$ is increasing at $h^{*}=1$. Such a high degree of inefficiency is feasible owing only to the frictions of the search economy, and not through a high value of government expenditures. ${ }^{7}$

As the subsequent sections will establish, the different properties of the two market settings are characterized by the wedge

$$
\omega=\frac{\frac{b}{2}\left(1+\frac{m(h)}{m(h)-2 \kappa h}\right)}{2 \kappa h},
$$

the ratio between after-tax labour income in the search economy and the Walrasian market setting. The properties of the wedge (level, first and second derivative) reflect the arguments discussed above. First, the level of this wedge describes the inefficiencies that lead to lower employment, as does a tax wedge. The larger the wedge is, the larger the inefficiencies are and the more likely a cycle becomes. Second, the shape of the wedge changes the shape of tax revenues (without changing utility). Specifically, the first and second derivatives of $\omega$ change $\frac{C S^{\prime \prime}}{C S^{\prime}}$ and thus the likelihood of a tax cycle as shown in equation (6). As is illustrated in panel $\mathrm{C}$ of Figure 2, the wedge is decreasing and convex so that $\frac{\omega^{\prime \prime}}{\omega^{\prime}}$ is negative and thus $\frac{C S^{\prime \prime}}{C S^{\prime}}$ is lower relative to the Walrasian setting. As shown in equation (6), this implies that a cycle leads to larger tax revenues and welfare is more likely to increase. As we will see, these two properties (decreasing and convex) are not specific to this example but characterize also other

7. The degree of inefficiencies will be substantially smaller in the calibrated search model in Section 6.1. 
economies: as the economy becomes more efficient-the number of vacancies increases-the wedge shrinks, and the speed of this convergence slows down.

This simple example shows that cycles can improve welfare and are more likely do so in an economy with frictions. The following sections generalize these insights. In the next section, I develop a framework to study optimal taxation in economies which feature more general form of frictions.

\section{THE FRAMEWORK}

In this section I describe the framework I use to study optimal policy both in models with and without frictions. Since this framework nests several classes of models that differ in the way they relate prices to allocations, I use a black box to formalize this relationship.

The economy is populated by a measure one of identical households. Each household's preferences over a stream of consumption, effort choices, and money holdings are described by a utility function

$$
\sum_{t=0}^{\infty} \beta^{t} u\left(c_{t}, h_{t}, m_{t}\right),
$$

where $c_{t}$ denotes consumption, $h_{t}$ denotes the effort choice (labour in the Lucas and Stokey (1983) (LS) economy), $m_{t}$ denotes real money holdings, and $\beta \in(0,1)$ denotes the subjective discount factor. The single-period utility function $u$ is assumed to be strictly increasing in $c_{t}$, strictly increasing in $m_{t}$ for $m_{t}<\bar{m}\left(c_{t}, h_{t}\right)$ and constant for $m_{t} \geq \bar{m}\left(c_{t}, h_{t}\right)$ ( $\bar{m}$ can be $\infty$ ) and strictly decreasing in $h_{t}$, strictly concave and three times continuously differentiable. The derivatives of period $t$ utility with respect to $c, m$, and $h$ are denoted $u_{c}(t), u_{m}(t)$, and $u_{h}(t)$, respectively.

The wage rate is $w_{t}$ and is taxed at the labour tax rate $\tau_{t}$ in period $t$. Households receive an after-tax real wage rate $\lambda_{t}^{L}=\left(1-\tau_{t}\right) w_{t}$ for providing effort $h$. Whereas in a Walrasian economy $\lambda_{t}^{L}=\frac{-u_{h}}{u_{c}}=\left(1-\tau_{t}\right) w_{t}$, frictions can invalidate these equalities, for example, as in the search economy in Section 2. The effort choice $h_{t}$ is transformed into consumption goods through a linear technology $F(h)=h$ at a resource cost $\gamma(h) .{ }^{8}$ Firms choose $h_{t}$ to maximize real profits $\Pi\left(h_{t}, w_{t}\right)$, which are fully taxed away.

In each period $t \geq 0$, households can buy one-period nominal government bonds $B_{t}$, which earn a nominal return $R_{t}$. Households also hold nominal money $M_{t}$, which at a price level $P_{t}$ is transformed into real balances $m_{t}=\frac{M_{t}}{P_{t}}$. The initial price level $P_{0}$ is normalized to 1 . Frictions also distort the acquisition of money, which in the presence of frictions is characterized through $\lambda_{t}^{M}=u_{c}(t) \frac{R_{t}-1}{R_{t}} \geq 0$, instead of $u_{m}(t)=u_{c}(t) \frac{R_{t}-1}{R_{t}}$ as in the frictionless case. Frictions thus drive a wedge between the opportunity cost of holding money and the marginal utility of money.

The household's flow budget constraint in period $t \geq 1$ is given by:

$$
P_{t} c_{t}+B_{t}+M_{t} \leq M_{t-1}+R_{t-1} B_{t-1}+P_{t} \lambda_{t}^{L} h_{t},
$$

where $R_{t} \geq 0$. The left-hand side of the budget constraint represents the uses of wealth: consumption spending, bond purchases, and money acquisition. The right-hand side shows the sources of wealth: bonds and money acquired in the previous period, plus labour income.

The household chooses $\left\{c_{t}, B_{t}\right\}_{t=0}^{\infty}$ to maximize (9), subject to (10), taking as given $\left\{R_{t}, \lambda_{t}^{L}, h_{t}, P_{t}, \lambda_{t}^{M}, M_{t}\right\}_{t=0}^{\infty}$, and initial wealth $R_{-1} B_{-1}+M_{-1}$.

8. A linear $F$ is without loss of generality. For a different technology just redefine the effort choice $\tilde{h}=F(h)$. 


\subsection{Government}

The government faces a stream of unproductive public consumption $g_{t}=g$. This is financed by levying labour income taxes at a rate $\tau_{t}$ and by issuing one-period bonds $B_{t}$ and nominal money $M_{t}$. The government's sequential budget constraint is given by

$$
B_{t}+M_{t}=R_{t-1} B_{t-1}+M_{t-1}+P_{t} g_{t}-\tau_{t} P_{t} w_{t} h_{t}-P_{t} \Pi\left(h_{t}, w_{t}\right) .
$$

\subsection{Equilibrium}

In the most general environment, the two wedges $\lambda^{L}$ and $\lambda^{M}$, depend on the whole history of events as in the quantitative analysis in Chari et al. (2007). For a theoretical analysis, however, this is too general and some restrictions are necessary. It seems natural to assume that the labour market wedge depends on the same variables as the Walrasian wage, namely on $h_{t}$, $\lambda^{L}\left(h_{t}\right) .{ }^{9}$ Similarly, the wedge in money acquisition depends on $M_{t} / P_{t}$ only, $\lambda^{M}\left(M_{t} / P_{t}\right)$.

An equilibrium $\left\{c_{t}, g_{t}=g, h_{t}, \tau_{t}, w_{t}, \lambda_{t}^{L}, \lambda_{t}^{M}, B_{t}, M_{t}, P_{t}, R_{t}\right\}_{t=0}^{\infty}$ then satisfies the following conditions:

$$
\begin{aligned}
c_{t}+g+\gamma(h) & =h_{t} \\
\lambda^{L}\left(h_{t}\right) & =w_{t}\left(1-\tau_{t}\right) \\
P_{t} c_{t}+B_{t}+M_{t} & =M_{t-1}+R_{t-1} B_{t-1}+P_{t} \lambda_{t}^{L} h_{t} \\
u_{c}(t) & =\beta \frac{R_{t} P_{t}}{P_{t+1}} u_{c}(t+1) \\
\lambda_{t}^{M}\left(m_{t}\right) & =u_{c}(t) \frac{R_{t}-1}{R_{t}} \\
h_{t} \text { maximizes } & \Pi\left(h_{t}, w_{t}\right) \\
R_{t} & \geq 0
\end{aligned}
$$

where (12) is the resource constraint, (13) describes an equilibrium in the labour market, (14) is the household's budget constraint, (15) is the consumption Euler equation, (16) describes money demand, (17) describes firm maximization, and (18) is the zero lower bound on nominal returns.

\section{OPTIMAL DYNAMIC POLICY}

In this section I consider whether implementing a constant policy is an optimal strategy for the government. I derive a condition to check whether a cycle is superior, and prove properties of such a non-deterministic policy.

\subsection{The Ramsey problem}

The Ramsey problem is the choice of an implementable allocation that maximizes welfare.

Definition 1. An allocation $\left\{c_{t}, h_{t}, m_{t}\right\}_{t=0}^{\infty}$ is implementable if $\left\{\tau_{t}, w_{t}, \lambda_{t}^{L}, \lambda_{t}^{M}, B_{t}, M_{t}, P_{t}\right.$, $\left.R_{t}\right\}_{t=0}^{\infty}$ exists, such that $\left\{c_{t}, g_{t}=g, h_{t}, \tau_{t}, w_{t}, \lambda_{t}^{L}, \lambda_{t}^{M}, B_{t}, M_{t}, P_{t}, R_{t}\right\}_{t=0}^{\infty}$ is an equilibrium.

Definition 2. The Ramsey solution is the welfare-maximizing implementable allocation.

9. The resource constraint implies that consumption need not be included on top of effort $h$. 
I now state the Ramsey problem in its primal-form representation (Lucas and Stokey, 1983). The basic idea is to use equilibrium conditions to express all prices and taxes as functions of allocations. Only the three variables, i.e. consumption, effort, and real money holdings, appear in the resulting primal form. This method allows all implementable allocations to be characterized by only two equations. The first of these is the resource constraint (12). To derive the second equation, I start with the intertemporal budget constraint of the representative household:

$$
\sum_{t=0}^{\infty} q_{t}\left[c_{t}+\frac{M_{t}-M_{t-1}}{P_{t}}-\lambda^{L}\left(h_{t}\right) h_{t}\right]=R_{-1} B_{-1},
$$

where $q_{t}:=P_{t} \prod_{i=0}^{t-1} \frac{1}{R_{i}}$. Using $\frac{q_{t}}{P_{t}}=R_{t} \frac{q_{t+1}}{P_{t+1}}$ and cancelling terms:

$$
\sum_{t=0}^{\infty} q_{t}\left[c_{t}-\lambda^{L}\left(h_{t}\right) h_{t}\right]+q_{t+1}\left(R_{t}-1\right) \frac{M_{t}}{P_{t+1}}=M_{-1}+R_{-1} B_{-1} .
$$

Since the individual's consumption Euler equation implies that

$$
q_{t}=\beta^{t} \frac{u_{c}(t)}{u_{c}(0)}
$$

and as optimal money acquisition implies

$$
\frac{q_{t+1}\left(R_{t}-1\right)}{P_{t+1}}=\frac{R_{t}-1}{R_{t}} \frac{q_{t}}{P_{t}}=\beta^{t} \frac{\lambda^{M}\left(m_{t}\right)}{P_{t} u_{c}(0)},
$$

I can substitute for $q_{t}$ and $R_{t}$. The budget constraint can then be written as

$$
\sum_{t=0}^{\infty} \beta^{t}\left[\frac{u_{c}(t)}{u_{c}(0)}\left(c_{t}-\lambda^{L}\left(h_{t}\right) h_{t}\right)+\frac{\lambda^{M}\left(m_{t}\right)}{u_{c}(0)} m_{t}\right]=M_{-1}+R_{-1} B_{-1},
$$

which is equivalent to the implementability constraint

$$
\sum_{t=0}^{\infty} \beta^{t}\left[u_{c}(t)\left(c_{t}-\lambda^{L}\left(h_{t}\right) h_{t}\right)+\lambda^{M}\left(m_{t}\right) m_{t}\right]=u_{c}(0)\left(M_{-1}+R_{-1} B_{-1}\right) .
$$

Proposition 1. For any $M_{-1}+R_{-1} B_{-1}$, an allocation $\left\{c_{t}, h_{t}, m_{t}\right\}_{t=0}^{\infty}$ is implementable if and only if

$$
\begin{aligned}
u_{c}(0)\left(M_{-1}+R_{-1} B_{-1}\right) & =\sum_{t=0}^{\infty} \beta^{t}\left[u_{c}(t)\left(c_{t}-\lambda^{L}\left(h_{t}\right) h_{t}\right)+\lambda^{M}\left(m_{t}\right) m_{t}\right] \\
c_{t}+g+\gamma\left(h_{t}\right) & =h_{t} .
\end{aligned}
$$

Proof. Uses the same arguments as in Lucas and Stokey (1983) or Chari and Kehoe (1999).

The Ramsey problem is to choose consumption $c_{t}$, effort $h_{t}$, and money $m_{t}$ to maximize (9), subject to equations (19) and (20). ${ }^{10}$ I restrict myself to $M_{-1}+R_{-1} B_{-1}=0$ in what follows

10. An upper bound on hours and money ensures that the objective function is bounded, and I proceed under the assumption that $g$ is not too large, so that the set of feasible policies is not empty. The same mathematical theorems (for example Tychonoff's theorem) as applied in Aiyagari (1994) then imply existence. 
since this makes period $t=0$ identical to all other periods $(t>0)$ and avoids any issues with time inconsistency. In a real model, all results hold without this assumption. In a model with money, it is well known (see for example, Chari and Kehoe, 1999) that it is necessary to set $M_{-1}+R_{-1} B_{-1}=0$ to make the problem interesting (otherwise the Ramsey planner confiscates the entire initial nominal wealth), and therefore I proceed under this assumption.

\subsection{A criterion for optimal cycles}

A reasonable guess for a stationary problem is that a time-invariant allocation is optimal.

Definition 3. A time-invariant allocation $(c, h, m)$ is an implementable sequence $\left\{c_{t}=\right.$ $\left.c, h_{t}=h, m_{t}=m\right\}_{t=0}^{\infty}$. An optimal time-invariant allocation $\left(h^{T I}, c^{T I}, m^{T I}\right)$ achieves the highest welfare among all time-invariant policies.

Optimality in the definition is conditional on being time-invariant (TI). ${ }^{11}$ The next theorem provides a condition for a TI policy not to be the solution to the Ramsey problem. Effort supply, consumption, and money are not constant in this case. Define

$$
C S\left(h_{t}, m_{t}\right)=u_{c}\left(h_{t}-g-\gamma\left(h_{t}\right), h_{t}, m_{t}\right)\left(h_{t}-g-\gamma\left(h_{t}\right)-\lambda^{L}\left(h_{t}\right) h_{t}\right)+\lambda^{M}\left(m_{t}\right) m_{t},
$$

the current value of period $t$ surplus and

$$
C U\left(h_{t}, m_{t}\right)=u\left(h_{t}-g-\gamma\left(h_{t}\right), h_{t}, m_{t}\right)
$$

the current value of period $t$ utility.

Theorem 1. Let $\left(h^{T I}, c^{T I}, m^{T I}\right)$ be the optimal TI allocation. If either

$$
\begin{array}{ccc}
C U_{h}\left(h^{T I}, m^{T I}\right) \neq 0 \quad \text { and } & \frac{C S_{h h}}{C U_{h h}}\left(h^{T I}, m^{T I}\right)-\frac{C S_{h}}{C U_{h}}\left(h^{T I}, m^{T I}\right)<0 \\
& \text { or } \\
C U_{m}\left(h^{T I}, m^{T I}\right) \neq 0 \quad \text { and } & \frac{C S_{m m}}{C U_{m m}}\left(h^{T I}, m^{T I}\right)-\frac{C S_{m}}{C U_{m}}\left(h^{T I}, m^{T I}\right)<0
\end{array}
$$

holds, then the optimal TI policy is not the solution to the Ramsey problem. A welfare-improving two-period cycle exists. ${ }^{12}$

The criterion in the theorem is equivalent to a second-order condition of the constrained maximization problem. ${ }^{13}$ The proof of the theorem instead uses a perturbation argument to show that a two-period cycle is welfare-improving. As will be made precise in the following sections, condition $(*)$ can be rewritten in terms of primitives (preferences, wedges, and the size of the government).

The main features of a simple time-varying policy can be conveyed in a two-period model without money. In the first period, labour taxes are lowered and debt is issued to balance the

11. The logic of the Laffer curve implies that there are multiple TI allocations but this multiplicity does not imply the existence of a cycle.

12. If $C U_{h h}=0$ set $\frac{C S_{h h}}{C U_{h h}}=\operatorname{sgn}\left(C S_{h h}\right) \infty$ and if $C U_{m m}=0$ set $\frac{C S_{m m}}{C U_{m m}}=\operatorname{sgn}\left(C S_{m m}\right) \infty$.

13. Accordingly, condition $(*)$ is only a local test since it depends on derivatives of $C U$ and $C S$ at $h^{T I}$ only. In particular, condition $(*)$ does not hold globally, so that a corner solution does not improve welfare. 
first-period budget. In the second period, the labour tax rate is increased to repay the debt (plus interest payments). The size of the necessary tax increase in the second period depends on the response of the real interest rate. Since labour supply and thus consumption increase in the first period and decrease in the second period, the consumption Euler equation implies that the real interest rate, interest payments, and the second-period tax rate decrease.

Condition $(*)$ reflects these arguments and indicates whether the benefits of a cycle outweigh its costs. Since utility is concave, $C U_{h h}\left(C U_{m m}\right)$ tells us how much households dislike cyclical consumption. As in the example in Section 2, $C S_{h h}\left(C S_{m m}\right)$ and $C S_{h}\left(C S_{m}\right)$ determine the decrease of average tax rates and the corresponding increase in average labour supply. ${ }^{14}$ Finally, $C U_{h}\left(C U_{m}\right)$ translates this increase in labour supply into an increase in utility if $h^{T I}\left(m^{T I}\right)$ is smaller than the efficient solution.

Condition $(*)$ is also related to the graphical analysis in Figure 1. Mathematically, both the tax curve and the indifference curve in Figure 1 describe $h_{2}$ as a function of $h_{1}$. The second-order derivative of this function equals $\frac{-C U_{h h}}{C U_{h}} \frac{(1+1 / \beta)}{\beta}$ for the indifference curve and $\frac{-C S_{h h}}{C S_{h}} \frac{(1+1 / \beta)}{\beta}$ for the tax curve. The graphical condition-namely that the tax curve is more convex than the indifference curve-can be expressed as $\frac{-C S_{h h} h^{T I}}{C S_{h}}>\frac{-C U_{h h} h^{T I}}{C U_{h}}$ and is thus equivalent to condition $(*)$.

\subsection{Properties of the Ramsey policy}

Theorem 1 shows the non-optimality of a TI policy through the existence of an improving cycle of length 2, but it is silent on the optimality of this cycle. The following theorem partially fills this gap. It states that the optimal policy implements only two different allocations $(h, m)$.

Theorem 2. The welfare of the optimal Ramsey solution can be arbitrarily well approximated by a policy that implements at most two different pairs $(h, m)$ if $\beta>1 / 2 .{ }^{15}$

The idea of the proof is to allow for a specific kind of randomization to convexify the problem and turn it into a linear programming problem. A well-known result in linear programming shows that the support of the optimal (randomizing) policy is not larger than 2 . It then remains to be shown that the optimal probability distribution of labour and money can be implemented by a sequence of tax rates. It is at this last step where, because of the specific choice of randomization, the assumption $\beta>1 / 2$ becomes relevant. An approximation is needed to rule out an infinite number of different tax rates.

\section{THE LUCAS AND STOKEY (1983) ECONOMY}

Here I consider whether implementing a constant tax rate is an optimal government strategy in the non-monetary Lucas and Stokey (1983) economy. This economy is nested in the more general framework, as Walrasian pricing implies that $\lambda^{L}=\frac{u_{h}}{u_{c}}$, firms maximize $h-w h$ and make zero profits in equilibrium, and $\gamma \equiv 0$.

14. The convexity of $C S(\cdot)$ is a necessary (but not sufficient) condition for a TI policy not to be optimal, since otherwise first-order conditions would be sufficient to characterize the Ramsey solution. With convexity of $C S$, there can be more than one solution to the first-order conditions.

15. Arbitrary approximation means that the difference between the welfare level (and the allocations) of the optimal Ramsey policy and the welfare level of a policy with two tax rates can be made smaller than any $\epsilon>0$. 
I can thus build on the general analysis in the previous section. The Ramsey problem is then to choose $\left\{c_{t}, h_{t}\right\}_{t=0}^{\infty}$ to maximize welfare subject to the implementability constraint

$$
u_{c}(0) R_{-1} B_{-1}=\sum_{t \geq 0} \beta^{t}\left(u_{c}(t) \cdot c_{t}+u_{h}(t) \cdot h_{t}\right)
$$

and the resource constraint

$$
c_{t}+g=h_{t} .
$$

\subsection{Time-invariant Ramsey policy}

The next theorem characterizes a class of utility functions for which the optimal TI policy is the Ramsey policy. ${ }^{16}$

Theorem 3. Let $u\left(c_{t}, h_{t}\right)=w\left(c_{t}\right)-\chi\left(h_{t}\right)$ where

- $w$ exhibits (weakly) increasing relative risk aversion (IRRA) and

- $\chi_{h}\left(h_{t}\right) \cdot h_{t}$ is a convex function of $h_{t}$.

Then the optimal TI policy is the Ramsey policy.

This theorem applies to classes of preferences considered by the literature (e.g. Lucas and Stokey, 1983; Chari and Kehoe, 1999). Preference specifications for $w$ include CRRA, CARA, and quadratic $w$. Standard assumptions on primitives do not imply that $\chi_{h}\left(h_{t}\right) \cdot h_{t}$ is convex. However, it is convex for standard choices such as $\chi\left(h_{t}\right)=\alpha \cdot h_{t}^{\theta}$ (for $\alpha>0, \theta \geq 1$ ), and $\chi\left(h_{t}\right)=-(T-h)^{1-\theta} /(1-\theta)$ (for $\theta>0$ and a time endowment $\left.T\right)$.

\subsection{Time-varying Ramsey policy}

The last section showed that time variation is not optimal for separable preferences that exhibit IRRA. However, this conclusion does not necessarily hold for the presumably relevant case of DRRA. The next theorem shows for non-separable preferences in the nested LS economy how criterion $(*)$ can be expressed in terms of elasticities. I derive this condition for non-separable preferences because it serves as a benchmark when economies with frictions are considered.

Define $\mu$ as the marginal utility of consumption, $\mu(h)=u_{c}(h-g, h), \chi$ as the marginal disutility of labour $\chi=-u_{h}(h-g, h)$, and $\epsilon_{f}$ as the elasticity of a function $f$ with respect to $h$, evaluated at $h^{T I}$. Let $\tau^{T I}$ be the tax rate in the optimal TI policy.

Theorem 4. For a utility function $u\left(c_{t}, h_{t}\right)$ let $\mu=u_{c}, \chi=-u_{h}$, and $\epsilon_{\mu^{\prime}}, \epsilon_{\mu}, \epsilon_{\chi^{\prime}}, \epsilon_{\chi}$ and $\tau^{T I}$ be as defined before. Then

$$
1+\frac{\epsilon_{\mu^{\prime}} \epsilon_{\mu}\left(1-\tau^{T I}\right)^{2}-\epsilon_{\chi^{\prime}} \epsilon_{\chi}\left(1-\tau^{T I}\right)^{2}}{\epsilon_{\mu}\left(1-\tau^{T I}\right)-\epsilon_{\chi}\left(1-\tau^{T I}\right)^{2}}+\frac{\epsilon_{\chi}\left(1-\tau^{T I}\right)-\epsilon_{\mu}\left(1-\tau^{T I}\right)}{\tau^{T I}}<0
$$

16. This result is not trivial since the implementability constraint need not be convex (for example, as in Case (II) in Figure 1). Furthermore, the well-known results by Judd (1985) and Chamley (1986), namely that steady-state capital income tax rates are zero, do not rule out cycles either. In case the optimality criterion $(*)$ implies that a (discontinuous) cycle should be implemented, a constant allocation is suboptimal. Thus a restriction to steady states is restrictive and cannot be detected through computing dynamics (eigenvalues) around this steady state because of the discontinuity. Furthermore, the result that non-steady-state capital income tax rates are zero (Chari and Kehoe, 1999) does not necessarily imply that labour tax rates are constant. 
implies that the optimal TI policy is not the solution to the Ramsey problem. A welfare-improving two-period cycle exists.

Condition (23) can be simplified for separable preferences. For $u\left(c_{t}, h_{t}\right)=w\left(c_{t}\right)-\chi\left(h_{t}\right)$ define $\kappa_{c}=\frac{w^{\prime \prime \prime} \cdot c}{w^{\prime \prime}}, \eta_{c}=\frac{w^{\prime \prime} \cdot c}{w^{\prime}}, \kappa_{h}=\frac{\chi^{\prime \prime \prime} \cdot h}{\chi^{\prime \prime}}$, and $\eta_{h}=\frac{\chi^{\prime \prime} \cdot h}{\chi^{\prime}}$ if the denominator is not zero. If the denominator equals zero, set $\kappa$ or $\eta$ to zero.

Theorem 5. Let $u\left(c_{t}, h_{t}\right)=w\left(c_{t}\right)-\chi\left(h_{t}\right)$ and $\kappa_{c}, \eta_{c}, \kappa_{h}, \eta_{h}$ and $\tau^{T I}$ be as defined before. Then

$$
1+\frac{\kappa_{c} \eta_{c}-\kappa_{h} \eta_{h}\left(1-\tau^{T I}\right)^{2}}{\eta_{c}-\eta_{h}\left(1-\tau^{T I}\right)^{2}}+\frac{\eta_{h}\left(1-\tau^{T I}\right)-\eta_{c}}{\tau^{T I}}<0
$$

implies that the optimal TI policy is not the solution to the Ramsey problem. A welfare-improving two-period cycle exists.

Condition (24) is identical to condition (23) except that the elasticities $\eta_{c}, \kappa_{c}, \eta_{h}, \kappa_{h}$ are replaced. If preferences are non-separable, households' willingness to substitute consumption over time not only depends on $c$ but also on $h$, and the disutility of labour also depends on $c$ and not only on $h$. For separable preferences, $\eta_{c}=\epsilon_{\mu}\left(1-\tau^{T I}\right), \kappa_{c}=\epsilon_{\mu^{\prime}}\left(1-\tau^{T I}\right), \eta_{h}=\epsilon_{\chi}$, and $\kappa_{h}=\epsilon_{v^{\prime}}$, so that theorem 5 is indeed nested in theorem $4 .{ }^{17}$

If in addition to preferences being separable, $\chi\left(h_{t}\right)=A \cdot h_{t}$-the Hansen (1985) preferences-then criterion (24) simplifies further:

Theorem 6. Let $u\left(c_{t}, h_{t}\right)=w\left(c_{t}\right)-A \cdot h_{t}$ and $\kappa_{c}, \eta_{c}$ and $\tau^{T I}$ be as defined before. Then

$$
1+\kappa_{c}<\eta_{c} / \tau^{T I}
$$

implies that the optimal TI policy is not the solution to the Ramsey problem. A welfare-improving two-period cycle exists.

DRRA is equivalent to $1+\kappa_{c} \leq \eta_{c}$. The criterion (25) says that DRRA has to be sufficiently strong. How strong depends on the size of $\tau^{T I}$. If $\tau^{T I}$ approaches 1 , a cycle would be optimal for all DRRA preferences, whereas $\tau^{T I}=0$ implies efficiency and no cycle at all. A cycle is welfare-enhancing if a variation in consumption leads to a variation in prices that is high enough to compensate for the household's aversion to this variation in consumption over time, given by $w^{\prime \prime}$. Since the period $t$ price of consumption equals $w^{\prime}$, the size of the price variation is high if $w^{\prime \prime \prime}$ is high. A cycle thus improves welfare if $w^{\prime \prime \prime}$ is large enough relative to $w^{\prime \prime}$, or equivalently if DRRA is strong enough. This reasoning is the same as in a model with precautionary savings. In such a setting, an increase in $\kappa_{c}$, for a fixed $\eta_{c}$, leads to a higher demand for precautionary savings since agents foresee that their relative risk aversion is higher in a high tax period, and they respond by demanding more bonds. Thus they are willing to accept a smaller return on their assets in response to a tax cycle.

The same arguments also underlie conditions (23) and (24) as sufficiently strong DRRA leads to cycles. How strong then also depends on the curvature of the disutility of labour. In

17. Abandoning the assumption of separability between labour and consumption can render a TI policy non-optimal even if the relative risk aversion is constant for a fixed $h$. This is, for example, the case when $u(c, h)=\left(c \cdot(3-h)^{2}\right)^{(1-\sigma)} /(1-\sigma)$. 
TABLE 1

Welfare gains in Lucas and Stokey (1983) with HARA utility

\begin{tabular}{lllllllr}
\hline$\eta$ & $\frac{{ }^{C y}}{c^{T I}}$ & $h^{T I}$ & $\underline{h}$ & $\bar{h}$ & $h^{*}$ & $a$ & $b$ \\
\hline$\kappa=-5$ & & & & & & & \\
-0.5 & 0.737 & 0.029 & 0.025 & 0.129 & 0.181 & -0.141 & 9.000 \\
-1.0 & 0.013 & 0.343 & 0.306 & 0.440 & 0.614 & -0.720 & 4.000 \\
-1.5 & 0.000 & 0.932 & 0.932 & 0.932 & 1.278 & -1.088 & 2.333 \\
\hline$\kappa=-9$ & & & & & & & \\
-0.5 & 9.470 & 0.0017 & 0.002 & 0.051 & 0.086 & -0.017 & 17.000 \\
-1.0 & 0.263 & 0.082 & 0.076 & 0.192 & 0.251 & -0.404 & 8.000 \\
-1.5 & 0.041 & 0.360 & 0.335 & 0.489 & 0.598 & -1.093 & 5.000 \\
\hline
\end{tabular}

Notes: $h^{T I}$ and $c^{T I}$ are the TI levels of $h$ and $c, h^{*}$ is the efficient level of $h, \underline{h}$ and $\bar{h}$ are implemented in a two-period cycle, and $c^{C y}$ is the constant level of $c$ that makes the representative household indifferent between consumption plans with and without a two-period tax cycle.

addition, $\kappa_{c}$ and $\eta_{c}$ need to be replaced in condition (23) because of non-separability. As a result, these conditions become more complicated than condition (25), which focuses purely on the role of DRRA.

Finally, I use the hyperbolic absolute risk aversion (HARA) utility function

$$
u(c, h)=\frac{(a+b c)^{b-1 / b}}{b-1}-h, \quad b \neq 1
$$

to compute the welfare gains in terms of consumption equivalents for a tax rate of $\tau=30 \%{ }^{18}$ As condition (25) states, cycles improve welfare only if $1+\kappa>\eta / \tau$ and welfare gains are larger as $1+\kappa-\eta / \tau$ becomes larger, where $\eta$ is risk version and $\kappa$ is prudence. Table 1 shows that welfare gains can be arbitrarily large depending on the values of $\eta=-0.5,-1.0,-1.5$ and $\kappa=-5,-9$.

So far I have characterized two classes of preferences, one for which time invariance is optimal, and one for which it is not. A possible response could be to restrict oneself to the class of preferences where first-order conditions are sufficient, and ignore the problem from then on. This may be a reasonable approach if the model being studied is the LS economy, yet this very often is not the case. Various frictions are built into models in monetary economics (for example, Lagos and Wright, 2005) and many models incorporate a labour market with search frictions (as in Pissarides, 2000). As the next section shows, the hope that results from the LS economy carry over to these more elaborated models, characterized by several frictions, is not warranted. Interestingly, I will show that the condition for cycles in the general framework is a generalization of condition (23), which allows for a precise description of when and why frictions cause cycles to be optimal.

\section{ECONOMIES WITH FRICTIONS}

In this section I consider tax cycles in economies with frictions. Applying the framework developed in Section 3, I allow for frictions in the labour/product market and in the money

18. As in Lucas (1987), this measure is defined as the percentage compensation required to make a household indifferent between consumption plans with and without a two-period tax cycle. Theorem 2 states that the optimal policy implements only two different levels of vacancies, but not necessarily a two-period cycle. Numerically, however, I was unable to find a policy that improves upon a two-period cycle. 
market. First I develop an optimality condition, nesting condition (23) in the previous section, for an economy with a labour wedge and for an economy with a money market wedge. Then I apply this theory to two specific economies, one a simple version of a (labour) search and matching economy and the other a Lagos and Wright (2005) monetary model. For both types of frictions, I find that a reasonable parametrization leads to the conclusion that cycles improve welfare. Using the theory, I explain why this conclusion is not unexpected, and suggest therefore that tax cycles are optimal in a large class of models with frictions. Finally, I summarize the results and discuss monopolistic competition, a friction that does not change the welfare properties of cycles.

\subsection{Frictions in the labour market}

Frictions in the labour market are characterized through a wedge $\omega$ between the after-tax wage $\lambda^{L}$ and the wage that would prevail with Walrasian pricing. To focus on the role of labour market frictions, I consider a non-monetary model. For a utility function $u(c, h)$ and a resource cost $\gamma(h)$, define the marginal utility of consumption

$$
\mu(h)=u_{c}(h-g-\gamma(h), h)
$$

and the marginal cost of implementing employment $h^{19}$

$$
\chi=-u_{h}(h-g-\gamma(h), h)+u_{c}(h-g-\gamma(h), h) \gamma^{\prime}(h) .
$$

The period $t$ wage $\mu_{t} \lambda_{t}$ is decomposed into the Walrasian component $\chi_{t}\left(=\mu_{t} \frac{\chi_{t}}{\mu_{t}}\right)$ and the wedge $\omega_{t}$,

$$
\mu_{t}(h) \lambda_{t}(h)=\omega_{t}(h) \chi_{t}(h)
$$

Welfare $C U$ and the surplus $C S$ then take the following form:

$$
\begin{aligned}
& C U(h)=u(h-g-\gamma(h), h), \\
& C S(h)=\mu(h) c(h)-\omega(h) \chi(h) h .
\end{aligned}
$$

The efficiency gap $\Delta=1-\frac{\chi}{w}$, which equals 0 for the efficient allocation and equals $\tau$ in the LS economy. The elasticity of a function $f$ with respect to $h$, evaluated at $h^{T I}$, is again denoted $\epsilon_{f}$. The resource constraint implies that $c(h)=h-g-\gamma(h)$.

Theorem 7. For a utility function $u\left(c_{t}, h_{t}\right)$ and a labour wedge $\omega$, define $\mu, \chi$, $\epsilon_{\mu^{\prime}}, \epsilon_{\mu}, \epsilon_{\chi^{\prime}}, \epsilon_{\chi}, \epsilon_{\omega^{\prime}}, \epsilon_{\omega}, \epsilon_{c^{\prime}}, \epsilon_{c}$, and $\Delta$ as before. Then

$\frac{\epsilon_{\mu^{\prime}} \epsilon_{\mu}+\epsilon_{c}\left(2 \epsilon_{\mu}+\epsilon_{c^{\prime}}\right)-\epsilon_{\chi^{\prime}} \epsilon_{\chi}-2 \epsilon_{\chi}-\epsilon_{\omega^{\prime}} \epsilon_{\omega}-2 \epsilon_{\omega} \epsilon_{\chi}-2 \epsilon_{\omega}}{\epsilon_{\mu}-\epsilon_{\chi}(1-\Delta)}<\frac{\epsilon_{\mu}-1+\epsilon_{c}-\epsilon_{\chi}-\epsilon_{\omega}}{\Delta} \quad\left(*^{L}\right)$

19. Both $\mu$ and $\chi$ are expressed as functions of $h$ only because the resource constraint implies that consumption $c(h)=h-g-\gamma(h)$. If employment generates disutility but no resource costs (as in the LS economy), $\chi=$ $-u_{h}(h-g-\gamma(h), h)$. If creating employment involves only resource costs and no disutility (as in a search economy), $\chi=u_{c}(h-g-\gamma(h), h) \gamma^{\prime}(h)$. In a Walrasian setting, the price of employment (the wage) would then equal $\frac{\chi}{\mu}$. 
implies that the optimal TI policy is not the solution to the Ramsey problem. A welfare-improving two-period cycle exists.

Theorem 7 generalizes Theorem 4. In the case of Walrasian pricing, $\omega=1$, and thus $\epsilon_{\omega}=0$ and $\epsilon_{\omega^{\prime}}=0$. If in addition there are no resource costs, $c=h-g$, condition $\left(*^{L}\right)$ simplifies to condition (23) in the previous section. ${ }^{20}$

Two differences between economies with and without frictions determine whether a cycle is more likely with frictions. First, the economy is less efficient if the wedge is positive $(\omega>1)$ as $h^{T I}$ is decreasing in $\omega$. In particular, as $\omega>1$ implies that $\Delta$ is positive even if $g=0$, a cycle can improve welfare if $g=0$ as shown in the example in Section 2. ${ }^{21}$ Second, the wedge is not constant, that is $\epsilon_{\omega} \neq 0, \epsilon_{\omega^{\prime}} \neq 0$. In the search economy in Section 2, the wedge is decreasing and convex, implying that the tax revenue curve is flatter, $C S_{h h} / C S_{h}$ is more negative, and cycles are more likely. I now consider whether the results from the example carry over to a more realistically calibrated search and matching economy.

6.1.1. A search and matching economy. I consider a search and matching model that is nested in the general framework and that generalizes the environment in example 2. Households derive utility $u(c)$ from consumption $c$ and firms post vacancies $v$ at a resource cost $\kappa$. At the beginning of each period, all workers are unmatched, eliminating unemployment as a state variable. The number of matches is given by a constant returns to scale Cobb-Douglas matching function $m\left(1, v_{t}\right)=\chi \cdot 1^{\alpha} v_{t}^{(1-\alpha)}=\chi \cdot v_{t}^{(1-\alpha)}$. The precise description of the environment is presented in the Appendix.

Proposition 2. For any $B_{-1}$, an allocation $\left\{c_{t}, v_{t}\right\}_{t=0}^{\infty}$ is implementable if and only if

$$
\begin{aligned}
& u_{c}(0) B_{-1}=\sum_{t \geq 0} \beta^{t} u_{c}(t)\left[c_{t}-\frac{b}{2} \frac{m\left(1, v_{t}\right) / v_{t}-\kappa}{\frac{1}{2} m\left(1, v_{t}\right) / v_{t}-\kappa} m\left(1, v_{t}\right)\right], \\
& c_{t}+g+\kappa v_{t}=m\left(1, v_{t}\right),
\end{aligned}
$$

where the first equality is the implementability constraint and the second one is the resource constraint. This model is nested in the general framework for $h=m(1, v)$, resource costs $\gamma=\kappa v$, and

$$
\lambda^{L}(v)=\frac{b}{2} \frac{m(1, v) / v-\kappa}{\frac{1}{2} m(1, v) / v-\kappa} .
$$

The Ramsey planner then maximizes $\sum_{t \geq 0} \beta^{t} u\left(c_{t}\right)$ over all implementable allocations.

I now consider a parameterized version of the model to check whether condition $\left(*^{L}\right)$ indicates the optimality of a cycle, using that the Walrasian component $\chi(v)=\mu(v) \frac{\kappa}{m^{\prime}(v)}$ and the wedge

$$
\omega(v)=\frac{\mu(v) \lambda_{L}(v)}{\chi(v)}=\frac{\lambda_{L}(v) m^{\prime}(v)}{\kappa} .
$$

20. In this case, $c=h-g$ implies $\epsilon_{c}=\frac{h}{c}=\frac{1}{(1-\tau)}=\frac{1}{(1-\Delta)}$, so that $\frac{2 \epsilon_{c} \epsilon_{\mu}-2 \epsilon_{\chi}}{\epsilon_{\mu}-\epsilon_{\chi}(1-\Delta)}=\frac{2}{1-\Delta} \frac{\epsilon_{\mu}-\epsilon_{\chi}(1-\Delta)}{\epsilon_{\mu}-\epsilon_{\chi}(1-\Delta)}=\frac{2}{1-\Delta}$.

21. $\epsilon_{\mu}-1+\epsilon_{c}-\epsilon_{\chi}-\epsilon_{\omega}$ is negative since the tax revenues are decreasing in $h$. 
TABLE 2

Parameters for cycles

\begin{tabular}{lllllll}
\hline$\alpha$ & 0.3 & 0.4 & 0.5 & 0.6 & 0.65 & 0.7 \\
$\sigma$ & 1.487 & 1.760 & 2.151 & 2.751 & 3.203 & 3.829 \\
\hline
\end{tabular}

The precise model parametrization is described in the Appendix. I choose government debt $B_{-1}=0$, government expenditures $g=0$, and the utility function is assumed to be

$$
u(c)=c^{1-\sigma} /(1-\sigma),
$$

a choice which implies no cycles in the LS economy. Table 2 reports, for every value of $\alpha$, the smallest value for $\sigma$, such that a cycle improves welfare. ${ }^{22}$

The reason why cycles are more likely in the search model than in the LS model is the same as in the simple example from Section 2. Wage formation is different from Walrasian pricing and the corresponding non-trivial wedge leads, for a given level of employment, to different tax revenues. The wedge again shrinks if the allocation becomes more efficient and is again convex since the speed of this convergence slows down, as I established in Section 2 (see panel $\mathrm{C}$ of Figure 2). The same properties of wedges thus seem to characterize many search and matching models and not only a certain example. Moreover, as I show in Section 6.2.1, the same properties hold in the case of frictions in money acquisition. The characterization of whether a deviation due to such a non-trivial wedge is large enough to make a cycle optimal is shown in criterion $\left(*^{L}\right)$, and confirmed numerically in Table 2 .

I now use the parameterized model to quantify the welfare effects, in terms of consumption equivalents, of implementing a two-period cycle. ${ }^{23}$ Figure 3 shows the results for values of $\sigma$ between 0 and 10 and different values of $\alpha=0.3,0.4,0.5,0.6,0.65$, and 0.7 . Each graph (for every $\alpha$ ) has a kink at the level of $\sigma$ as computed in Table 2. For all values of $\sigma$ below this level, there is no welfare gain from a cycle. For higher values of $\sigma$, the welfare gains are positive with a maximum level of $0.7 \% .^{24}$ The fact that unemployment cannot be negative puts an upper bound on the welfare gains. ${ }^{25}$ The optimal two-period cycle implements zero unemployment and a small negative tax rate in the low tax period, and in the high tax period an unemployment level slightly above the time invariant level of $5.6 \%$ and a small positive tax rate. For example, if $\alpha=0.5$ and $\sigma=10$, the welfare gain equals $0.64 \%$, the unemployment rates are $0 \%$ and $8.1 \%$, and the tax rates equal $-0.3 \%$ and $0.1 \%$.

\subsection{Frictions in monetary economies}

Frictions in the acquisition of money are characterized by a wedge $\omega$ which changes the decision to acquire money, $\omega=\frac{\lambda^{M}}{u_{m}}$. To focus on these specific frictions, I consider a frictionless labour

22. The values of $\sigma$ are within the range used in the macro literature (McGrattan et al. (1997), Chari et al. (2002), and Gali et al. (2003) all use substantially higher values).

23. The calibration strategy follows Shimer (2005) and Hagedorn and Manovskii (2008).

24. The graphs are ordered by $\alpha$, the elasticity parameter in the matching function. For smaller values of $\alpha$, employment becomes more responsive to changes in vacancies $\left(E=m(1, v)=\chi v^{1-\alpha}\right)$ and welfare gains from a cycle are larger. For example, in the extreme case of $\alpha=1$, employment would be constant and policy would be ineffective, whereas employment would be a linear function of vacancies if $\alpha=0$.

25. The inefficiencies (due to $5.6 \%$ of households not working) seem to be small relative to the potential inefficiencies caused by taxation. Prescott (2004) argues that differences in marginal tax rates alone potentially explain why Americans work 50\% more than their German, French, and Italian counterparts. 


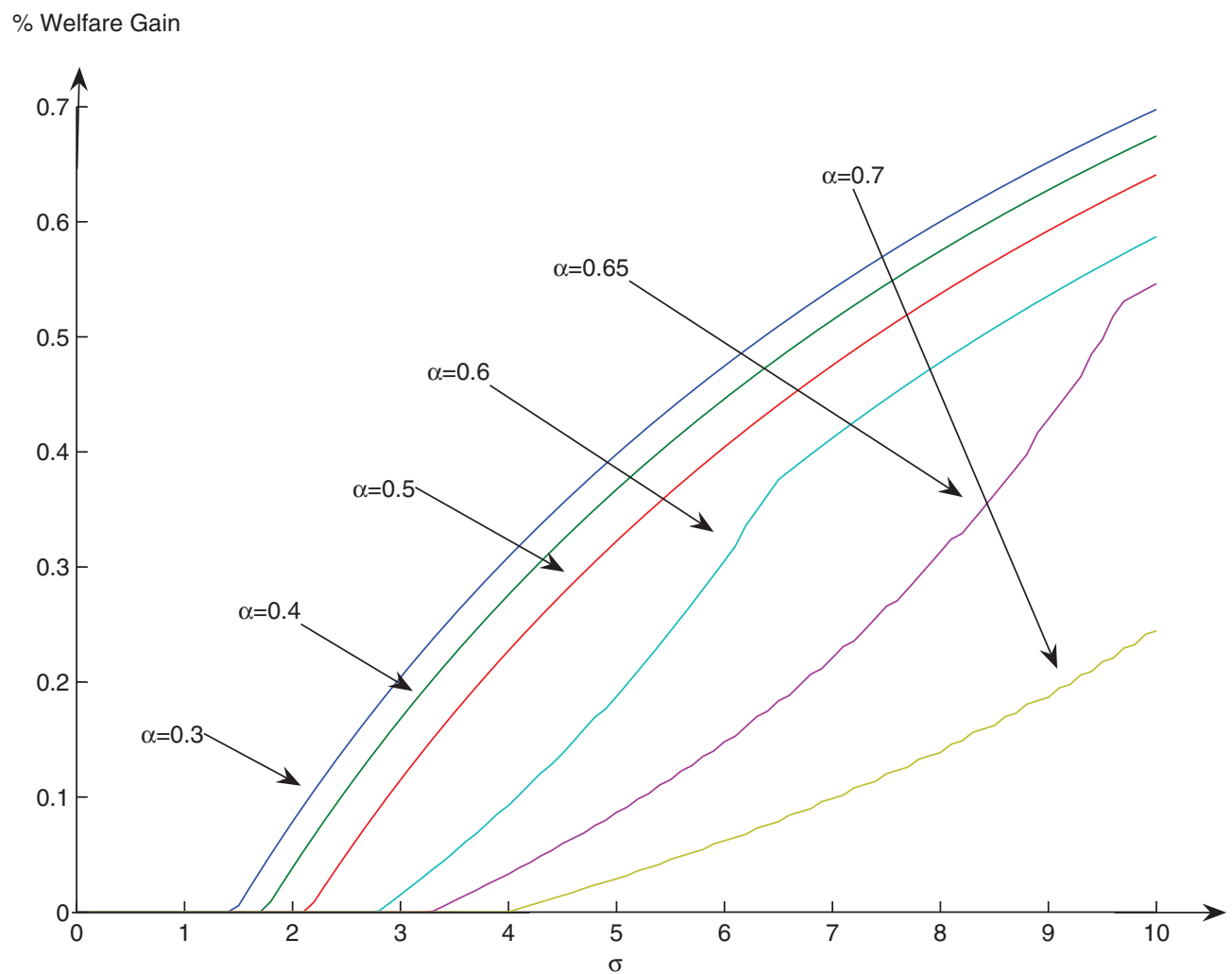

FIGURE 3

Welfare gains from a two-period cycle in a labour search model

market. The elasticity of a function with respect to $m$, evaluated at the TI solution $\left(h^{T I}, m^{T I}\right)$ ( $u$ can be non-separable), is again denoted $\epsilon_{f}$. Set $\mu\left(h_{t}, m_{t}\right)=u_{m}\left(h_{t}-g, h_{t}, m_{t}\right)$.

Theorem 8. For a utility function $u\left(c_{t}, h_{t}, m_{t}\right)$ and a money acquisition wedge $\omega$, define $\mu, \epsilon_{\mu^{\prime}}, \epsilon_{\mu}, \epsilon_{\omega^{\prime}}, \epsilon_{\omega}$ as before. If $m^{T I}<\bar{m}$ and $R^{T I}>0$ (Friedman rule is not optimal), then

$$
\frac{\epsilon_{\omega^{\prime}} \epsilon_{\omega}}{\epsilon_{\mu}}+2 \epsilon_{\omega}\left(1+\frac{1}{\epsilon_{\mu}}\right)+2+\epsilon_{\mu^{\prime}}-\left(\epsilon_{\mu}+\epsilon_{\omega}+1\right)<0 \quad\left(*^{M}\right)
$$

implies that the optimal TI policy is not the solution to the Ramsey problem. A welfare-improving two-period cycle exists.

A primary role of frictions is to rule out the Friedman rule as an optimal policy. A cycle requires that a decrease of $R$ (or an increase in $m$ ) is feasible, which is the case if the zero bound on nominal interest rates is not binding. The Friedman rule is, however, a prevalent result in frictionless economies (Chari and Kehoe, 1999), so that frictions are almost a necessary condition. A second contribution of frictions is that the wedge changes the shape of the tax revenue curve. Without frictions and thus with a constant wedge equal to 1 , condition $\left(*^{M}\right)$ would read

$$
1+\epsilon_{\mu^{\prime}}-\epsilon_{\mu}<0
$$

(C) 2010 The Review of Economic Studies Limited 


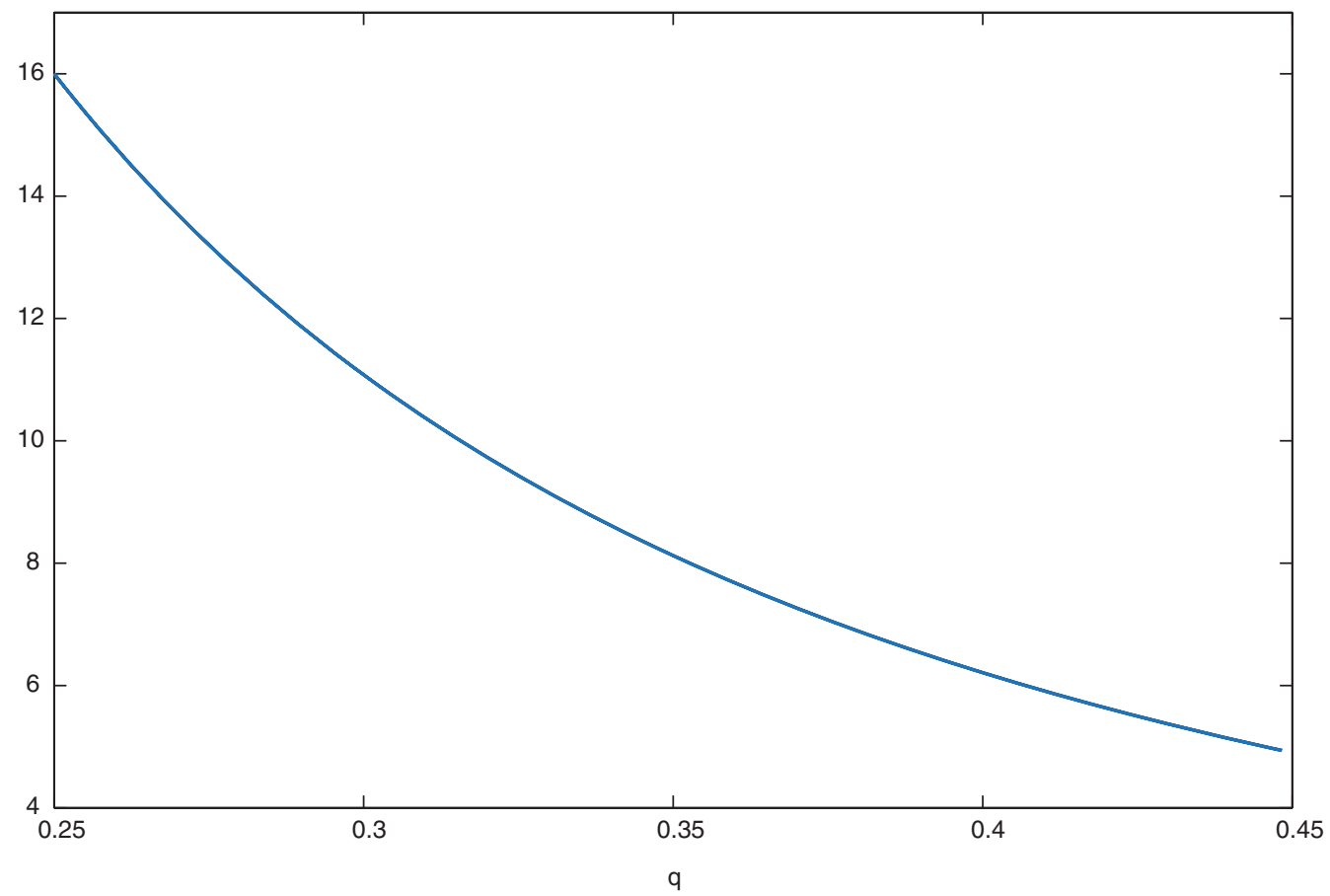

FIGURE 4

The wedge in Lagos and Wright (2005)

or equivalently, the contribution of frictions is to change this condition by

$$
\frac{\epsilon_{\omega^{\prime}} \epsilon_{\omega}}{\epsilon_{\mu}}+2 \epsilon_{\omega}\left(1+\frac{1}{\epsilon_{\mu}}\right)-\epsilon_{\omega}
$$

A positive wedge $(\omega>1)$ suggests that $\omega$ is decreasing and convex, as will be true for the Lagos and Wright (2005) economy. It is decreasing because the wedge disappears when $R$ converges to 1 (Friedman rule). This convergence is convex whenever the speed of convergence is slower the closer $R$ is to the Friedman rule. Interestingly, the same arguments established the shape of the wedge in the search and matching model. Figure 4 shows the wedge with these properties for a parameterized version of Lagos and Wright (2005). The contribution of frictions to condition $\left(*^{M}\right)$ (equation (32)) is then negative, explaining why a cycle is welfare-improving.

I now consider a specific economy, Lagos and Wright (2005), which fits into the framework developed in Section 3 and makes Theorem 8 applicable. I choose this model because it provides an analytically tractable framework for dealing with frictions in the acquisition of money (which arise due to frictions in the product and credit markets).

6.2.1. The Lagos and Wright (2005) monetary model. Every period is divided into two subperiods. In the first subperiod, agents trade in a frictionless market, the centralized market (CM), followed by a subperiod with trading frictions, the decentralized market (DM). With probability $\alpha$, the household wants to buy a good $q$ in the DM, which gives it utility $u(q)$; with probability $\alpha$, the household is a seller with cost function $c(q)$; and with probability $1-2 \alpha$ the household does not participate in the DM. Money is needed in all transactions in the 
DM. $^{26}$ The price and the quantity traded are the outcomes of Nash bargaining with bargaining power $\theta$ for the buyer. The function

$$
z(q)=\frac{\theta c(q) u^{\prime}(q)+(1-\theta) u(q) c^{\prime}(q)}{\theta u^{\prime}(q)+(1-\theta) c^{\prime}(q)},
$$

describes how $q$ is monotonically related to money holdings. The precise description of the environment is presented in the Appendix. I now characterize the set of implementable allocations, which are, as is standard, equivalently expressed in terms of $q$ instead of in terms of $m$ (see Aruoba and Chugh, 2006).

Proposition 3. For any $\left(B_{-1}, M_{-1}\right)$, an allocation $\left\{c_{t}, h_{t}, q_{t}\right\}_{t=0}^{\infty}$ is implementable if and only if

$$
\begin{aligned}
U_{c}\left(c_{0}\right) \frac{M_{-1}+R_{-1} B_{-1}}{P_{0}} & =\sum_{t \geq 0} \beta^{t}\left\{U_{c}\left(c_{t}\right) c_{t}-A h_{t}+\alpha q_{t}\left(\frac{u^{\prime}\left(q_{t}\right)}{\epsilon_{z, q}}-\frac{z\left(q_{t}\right)}{q_{t}}\right)\right\} \\
c_{t}+g & =h_{t} \\
\frac{u^{\prime}\left(q_{t}\right)}{z^{\prime}\left(q_{t}\right)} & \geq 1 .
\end{aligned}
$$

The nominal interest $R_{t+1}$ equals $\alpha\left(\frac{u^{\prime}\left(q_{t}\right)}{z^{\prime}\left(q_{t}\right)}-1\right)+1$, so that equation (36) is equivalent to a zero bound on nominal interest rates and government's seignorage $\frac{\frac{\alpha q_{t} u^{\prime}\left(q_{t}\right)}{\epsilon_{z}, q}-\alpha z\left(q_{t}\right)}{U_{c}\left(c_{t}\right)}=\frac{M_{t}}{P_{t}} \frac{R_{t}-1}{R_{t}}$. Interestingly, $\epsilon_{z, q}$ is equal to $1+\epsilon_{p, q}$, where $p(q)$ is the price of the good traded in the DM. Whenever this price depends on the quantity traded, the shape of the wedge and the tax revenue curve will change. A non-zero price elasticity is thus a key ingredient for the optimality of a cycle. In the corresponding Walrasian setting,

$$
\lambda^{M}=\alpha\left(\frac{u^{\prime}(q)}{\epsilon_{z, q}}-\frac{z(q)}{q}\right)
$$

is replaced by the marginal value of $q, \alpha\left(u^{\prime}-c^{\prime}\right)$, so that the price elasticity does not play a role in this case. The wedge $\omega$, which characterizes the frictions, then equals

$$
\omega=\frac{\lambda^{M}}{\alpha\left(u^{\prime}-c^{\prime}\right)}=\frac{u^{\prime}\left(q_{t}\right)}{\epsilon_{z, q}\left(u^{\prime}-c^{\prime}\right)}-\frac{z(q)}{q\left(u^{\prime}-c^{\prime}\right)}
$$

and the Ramsey allocation maximizes

$$
\sum_{t \geq 0} \beta^{t}\left\{U\left(c_{t}\right)-A h_{t}+\alpha\left(u\left(q_{t}\right)-c\left(q_{t}\right)\right)\right\}
$$

over all implementable allocations.

I now use criterion $\left(*^{M}\right)$ to assess numerically whether a cycle improves welfare, making it necessary to choose functional forms for $U, u$ and $c$ and values for the remaining parameters. In the CM I set $U(c)=\log (c), A=1 / 2$, and in the DM, the utility function equals $u(q)=$

26. One can think of "money" as cash (as in Lagos and Wright, 2005) or as bonds (as in Lagos, 2005). 
TABLE 3

Results from the parametrization

\begin{tabular}{lcccccc}
\hline$\theta$ & $\frac{q^{C y}}{q^{T I}}$ & $q^{T I}$ & $\frac{g}{h^{T I}}$ & $\frac{D M}{Y=D M+C M}$ & $\frac{m^{T I}}{h^{T I}+\alpha m^{T I}}$ & $\frac{\partial m}{\partial R} \frac{R}{m}$ \\
\hline$g=0.3, \eta=2$ & & & & & & \\
0.5 & 1.225 & 0.138 & 0.135 & 0.026 & 0.261 & -0.213 \\
0.75 & 1.096 & 0.199 & 0.135 & 0.026 & 0.262 & -0.228 \\
1 & 1.007 & 0.272 & 0.134 & 0.026 & 0.261 & -0.221 \\
\hline$g=0.4, \eta=2$ & & & & & \\
0.5 & 1.406 & 0.109 & 0.170 & 0.026 & 0.256 & -0.107 \\
0.75 & 1.192 & 0.165 & 0.171 & 0.026 & 0.258 & -0.128 \\
1 & 1.041 & 0.235 & 0.170 & 0.026 & 0.258 & -0.140 \\
\hline$g=0.4, \eta=1$ & & & & & \\
0.5 & 1.492 & 0.131 & 0.172 & 0.023 & 0.226 & -0.199 \\
0.75 & 1.212 & 0.206 & 0.173 & 0.023 & 0.231 & -0.261 \\
1 & 1.048 & 0.292 & 0.172 & 0.023 & 0.231 & -0.289 \\
\hline
\end{tabular}

Notes: $q^{T I}, h^{T I}$, and $c^{T I}$ are the TI levels of $q, h$, and $c . q^{C y}$ is the constant level of $q$ that makes the representative household indifferent between consumption plans with and without a two-period tax cycle. $\frac{D M}{Y=D M+C M}$ is the fraction of output $Y$ produced in the DM, $\frac{m^{T I}}{h^{T T}+\alpha m^{T T}}$ is the inverse of money velocity, and $\frac{\partial m}{\partial R} \frac{R}{m}$ is the elasticity of money demand.

$\frac{(q+\kappa)^{1-\eta}-\kappa^{1-\eta}}{1-\eta}+1$, the cost function $c(q)=\exp \left(q^{2} / 2\right), \kappa=1$ and $\alpha=0.1{ }^{27}$ These choices rule out cycles in the corresponding Walrasian economy.

I then vary the three remaining parameters, $\eta$ (the curvature parameter of $u$ ), $\theta$ (the bargaining power of the buyer), and $g$ (government expenditures). ${ }^{28}$ Table 3 reports the results such as the size of the CM, the share of government expenditure and the elasticity of money demand. The velocity of money and the elasticity of money demand seem to be reasonable and the size of the government is quite small, between $13 \%$ and $17 \%$ of CM output. The time-invariant $q$ is denoted $q^{T I}$ and $q^{C y}$ is the constant level of $q$ that makes the representative household indifferent between consumption plans with and without a two-period tax cycle. The percentage gain $\frac{q^{C y}}{q^{T T}}$ of a cycle in terms of DM consumption is quite large. For example, for $g=0.4$ and $\eta=1$ ( $\log$ preferences), the consumption gain in the DM, $\frac{q^{C y}}{q^{T I}}$, is close to $50 \%$. The welfare gain can be expressed also in terms of CM consumption. A household is indifferent between $3.97 \%$ higher consumption in the CM and a two-period cycle. Figure 5 provides more information about how the welfare gains from a two-period cycle vary with $\eta$ and $\theta$. The figure shows $\frac{q^{C y}}{q^{T T}}$ as a function of $\eta$ for $\theta=0.5,0.75,1$ and $g=0.3,0.4$.

As already observed, a higher value of $\eta$ unambiguously makes a cycle more likely to be optimal. However, a larger $\eta$ also makes households more averse to cycles, so that the size of the cycle eventually diminishes. A lower value of $\theta$ (a smaller buyer's share of the surplus

27. To guarantee existence of an equilibrium in Lagos and Wright $(2005)(u(0)=c(0)$ is finite) it is necessary to add $\kappa$ and a 1 to the utility function.

28. These choices could be guided by two observations in the data, the demand elasticity of $M$ and the level of velocity, i.e. nominal output divided by $M$. However, these numbers depend on the interpretation of $M$ in the data. For example, the velocity of bonds is much lower than the velocity of M1. The elasticity of money also depends on the time period. For example, the correlation between $M 1 / G D P$ and a short-term nominal interest rate has been positive for the last 25 years, although previously it was negative. 

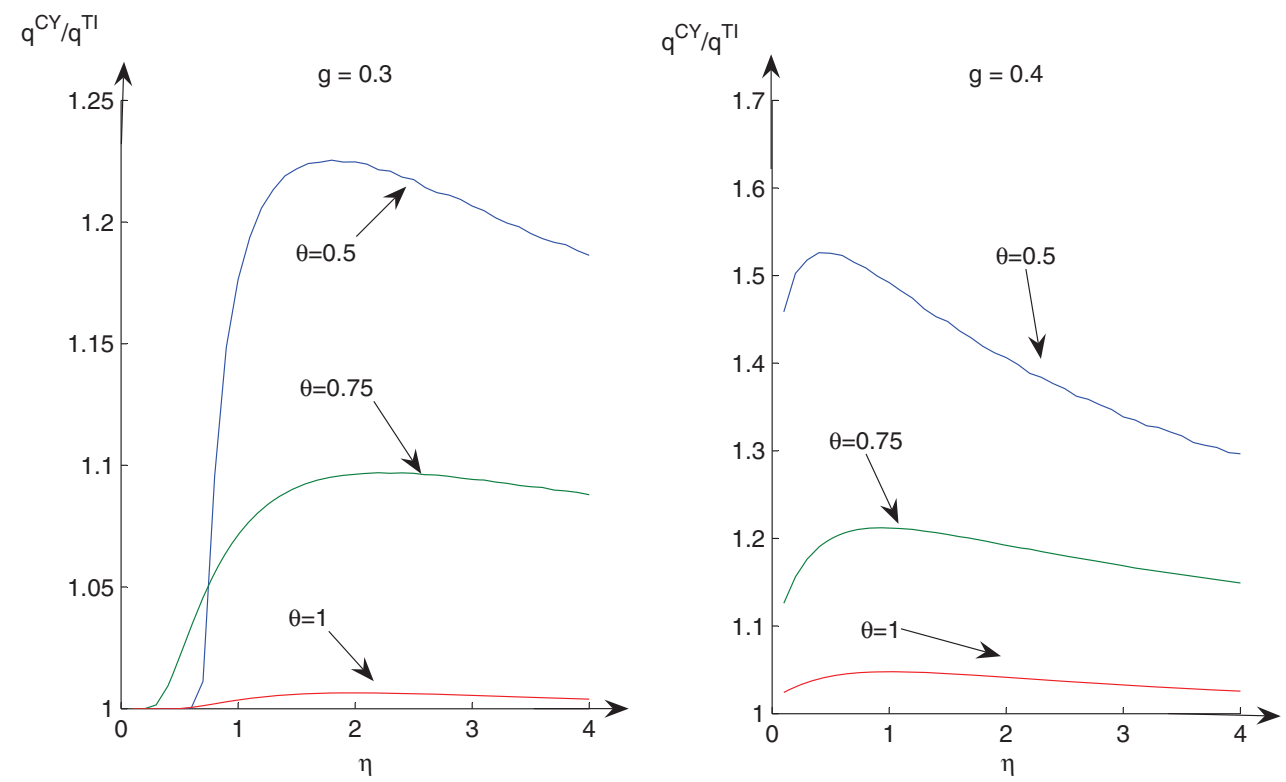

FIGURE 5

Welfare gains from a two-period cycle in Lagos and Wright (2005)

in the DM) leads to less trade in the DM, so that an increase in trade and a cycle are more valuable.

For this parameterized model, criterion $\left(*^{M}\right)$ can be used to understand the role of frictions. Table 4 shows the value of this criterion in the LW model and in the corresponding frictionless economy. As a negative value indicates a cycle, Table 4 establishes that cycles are welfareimproving only in the model with frictions. The table also demonstrates that this difference between the two economies with and without frictions is due both to a non-trivial wedge $\omega$ and to the non-zero elasticities of $\omega$ and $\omega^{\prime} .^{29}$

\subsection{Summary}

A general lesson to be learned from these two classes of economies (with frictions in the labour market and in money acquisition) is that price formation is key. This lesson can be applied to other frictions too. Whenever after-tax prices are not equal to the household's marginal rate of substitution, the properties of cycles in such an economy differ from those in the corresponding Walrasian economy. In a search and matching model, the wage is located between productivity and the marginal rate of substitution. The exact location depends on the form of bargaining, but usually it does not equal the marginal rate of substitution. In the monetary economy, the marginal cost of holding money typically is not equal to the marginal benefit of holding money, $\lambda^{M} \neq u_{m}$. In both cases, tax revenues (but not utility) change and conditions $\left(*^{L}\right)$ and $\left(*^{M}\right)$ describe why and when this change makes cycles welfare-improving.

29. Aruoba and Chugh (2006) consider optimal taxation in the same model but their choice of functional forms makes the model with frictions look identical to the Walrasian benchmark. Their critical assumption is that the cost function is linear, $c(q)=q$. This choice eliminates price effects $\epsilon_{z, q}=1+\epsilon_{p, q}=1$, and implies that $\frac{u^{\prime}(q)}{\epsilon_{z, q}}-\frac{z(q)}{q}$ equals $u^{\prime}(q)-1=u^{\prime}(q)-c^{\prime}(q)$, just as in the Walrasian case. Thus $\omega=1$ and cycles are not improving welfare. 
TABLE 4

The role of frictions

\begin{tabular}{lccccc}
\hline$\theta$ & $\left(*^{M}\right)$ & $\left(*^{M}\right)$ (Walras) & $\omega$ & $\epsilon_{\omega, q}$ & $\epsilon_{\omega^{\prime}, q}$ \\
\hline$g=0.3, \eta=2$ & & & & & \\
0.5 & -6.065 & 1.336 & 12.955 & -2.492 & -3.022 \\
0.75 & -3.226 & 1.694 & 11.773 & -2.473 & -2.890 \\
1 & -0.674 & 2.507 & 13.497 & -2.000 & -3.000 \\
\hline$g=0.4, \eta=2$ & & & & & \\
0.5 & -7.384 & 1.224 & 22.822 & -2.298 & -3.052 \\
0.75 & -4.200 & 1.471 & 18.402 & -2.285 & -2.990 \\
1 & -1.617 & 2.020 & 18.060 & -2.000 & -3.000 \\
\hline$g=0.4, \eta=1$ & & & & & \\
0.5 & -8.307 & 1.244 & 16.413 & -2.222 & -3.041 \\
0.75 & -4.422 & 1.526 & 12.293 & -2.217 & -2.984 \\
1 & -1.774 & 2.081 & 11.718 & -2.000 & -3.000 \\
\hline
\end{tabular}

Another popular deviation from a Walrasian world is monopolistic competition. This friction drives a wedge between productivity and wages as firms charge a mark-up. However, monopolistic competition does not change the welfare properties of cycles. The reason is simple. The implementability constraint takes the same form with or without monopolistic competition since the after-tax wage does not change or, equivalently, the price of households' leisure does not change. Whatever the tax rate on wages or the degree of monopolisitc competition, households require the same compensation for a given amount of labour. In the notation of the general framework, $\lambda^{L}=-\frac{u_{h}}{u_{c}}$, that is the wedge $\omega=1$. As a result and consistent with the general lesson, tax revenues as a function of $h$ do not change and thus cycles do not become more likely.

\section{CONCLUSIONS}

This paper asks whether tax smoothing, as suggested by Barro (1979), or rather tax cycles represent the solution to a Ramsey taxation problem in models with frictions. There is no extrinsic uncertainty that would result in cycles.

To study this question, I develop a framework that nests both a frictionless Walrasian benchmark economy and a large class of models with frictions. Frictions are modelled through wedges between prices and marginal rates of substitution. These wedges distort agents' decisions in the labour market and in the product market, and their decisions to acquire money. I derive a sufficient condition for tax cycles to be welfare-improving in the general framework, which is then applicable to a Walrasian economy and to a large class of models with frictions. Through the shape of the wedges characterizing these models, this criterion illustrates the different welfare properties of tax cycles in models with and without frictions.

Applying the framework to the frictionless benchmark economy, I find that under sufficiently strongly decreasing relative risk aversion (DRRA) tax cycles are optimal, whereas under increasing relative risk aversion (IRRA) they are not. I then apply the framework to two models with frictions. I theoretically characterize the properties of the wedges that result in cycles for frictions in the labour market, in the product market, and in money acquisition. Then I consider calibrated examples that are relevant in many models and are nested in my framework. For a labour search and matching economy and the Lagos and Wright (2005) monetary economy, I demonstrate how a cycle now becomes optimal for a class of preferences 
that was considered to imply the opposite in a frictionless Walrasian world. Thus the results that have been established for the Walrasian economy, which guaranteed optimal tax smoothing for a certain class of preferences, prove not to carry over to a large class of models. Interestingly, these preferences include constant relative risk aversion, the preference of choice in many papers. My results suggest the possibility that tax cycles can improve welfare, in particular in models with frictions.

Another interesting example-not discussed in this paper-where tax cycles are welfareimproving is considered in Barbie et al. (2009). This paper characterizes optimal redistribution with a linear labour tax in a frictionless model with heterogenous preferences as in Judd (1985). We find that a tax cycle implicitly serves as a redistributional device and can improve welfare even if all agents have CRRA preferences.

\section{APPENDIX}

Proof of Theorem 1. The proof for cycles in labour $h$ and money $m$ are identical. I therefore consider the case of $h$ only and omit any references to $m$. First- and second-order derivatives are denoted $C U^{\prime}=C U_{h}, C U^{\prime \prime}=C U_{h h}$, $C S^{\prime}=C S_{h}$, and $C S^{\prime}=C S_{h h}$.

In principle, four cases have to be considered. Labour supply can be too high $\left(C U^{\prime}<0\right)$ or too low $\left(C U^{\prime}>0\right)$, and tax revenue can be increasing $\left(C S^{\prime}>0\right)$ or decreasing $\left(C S^{\prime}<0\right)$ in $h$ (the case $C S^{\prime}=0$ is considered below). Two cases can be ruled out immediately if transfers from the government to the household are allowed for (this means the implementability constraint becomes an inequality constraint; I use this "trick" later). If $C U^{\prime}>0$ and $C S^{\prime}>0$, an increase in labour supply is welfare-improving and raises tax revenues. Conversely, if $C U^{\prime}<0$ and $C S^{\prime}<0$, a decrease in labour supply is welfare-improving and raises tax revenues. Two cases remain. In Case I, the labour supply is too low $\left(C U^{\prime}>0\right)$ and cutting taxes decreases tax revenue $\left(C S^{\prime}<0\right)$. In Case II, labour supply is too high $\left(C U^{\prime}<0\right)$ and the economy is on the downside of the Laffer curve, so that lowering taxes increases tax revenue $\left(C S^{\prime}>0\right)$. In Case I, $(*)$ is equivalent to

$$
\frac{C S^{\prime \prime}}{C S^{\prime}}\left(h^{T I}\right)-\frac{C U^{\prime \prime}}{C U^{\prime}}\left(h^{T I}\right)<0 \quad\left(*^{I}\right)
$$

and in Case II, $(*)$ is equivalent to

$$
\frac{C S^{\prime \prime}}{C S^{\prime}}\left(h^{T I}\right)-\frac{C U^{\prime \prime}}{C U^{\prime}}\left(h^{T I}\right)>0 \quad\left(*^{I I}\right) .
$$

I use a perturbation argument to show that a TI policy is not optimal. Consider two consecutive periods $(t$ and $t+1)$ where the same amount of labour $h^{T I}$ is implemented. In the first period, labour supply is increased by $\Delta \geq 0$. In the second period, labour supply is decreased by $\delta / \beta \geq 0$. Let $S(\Delta, \delta)$ be the present value surplus and $V(\Delta, \delta)$ the present value utility from these two periods (evaluated at $h^{T I}$ ). Thus

$$
\begin{aligned}
S(\Delta, \delta) & =C S\left(h^{T I}+\Delta\right)+\beta \cdot C S\left(h^{T I}-\delta / \beta\right) \\
V(\Delta, \delta) & =C U\left(h^{T I}+\Delta\right)+\beta \cdot C U\left(h^{T I}-\delta / \beta\right) .
\end{aligned}
$$

For small $\Delta$, define $\delta^{S}(\Delta)$ and $\delta^{V}(\Delta)$ such that

$$
\begin{aligned}
S\left(\Delta, \delta^{S}(\Delta)\right) & =0 \\
V\left(\Delta, \delta^{V}(\Delta)\right) & =0 .
\end{aligned}
$$

If multiple solutions exist, the smallest $\delta$ is chosen. Define $\delta^{*}(\Delta)=\left(\delta^{S}(\Delta)+\delta^{V}(\Delta)\right) / 2$.

If condition $(*)$ holds, it will be shown that for small $\Delta$, a joint increase by $\Delta$ in the first period and a decrease by $\delta(\Delta) / \beta$ in the second period increase both $S$ and $V$. An increase in $S$ means that this policy change is implementable by Proposition 1, while an increase in $V$ means that this policy change is welfare-improving.

Thus let $\tilde{S}$ and $\tilde{B}$ be defined as follows:

$$
\begin{aligned}
\tilde{S}(\Delta) & =S\left(\Delta, \delta^{*}(\Delta)\right) \\
\tilde{V}(\Delta) & =V\left(\Delta, \delta^{*}(\Delta)\right) .
\end{aligned}
$$

(C) 2010 The Review of Economic Studies Limited 
Obviously $\delta^{*}(0)=\left(\delta^{S}(0)+\delta^{V}(0)\right) / 2=0$. Implicit differentiation results in:

$$
\begin{aligned}
\frac{\partial \delta^{*}(\cdot)}{\partial \Delta}(0)=\frac{\partial \delta^{S}(\cdot)}{\partial \Delta}(0)=\frac{\partial \delta^{V}(\cdot)}{\partial \Delta}(0) & =1 \\
\frac{\partial^{2} \delta^{S}(\cdot)}{\partial \Delta \partial \Delta}(0) & =\frac{(1+\beta) \cdot C S^{\prime \prime}\left(h^{T I}\right)}{\beta \cdot C S^{\prime}\left(h^{T I}\right)} \\
\frac{\partial^{2} \delta^{V}(\cdot)}{\partial \Delta \partial \Delta}(0) & =\frac{(1+\beta) \cdot C U^{\prime \prime}\left(h^{T I}\right)}{\beta \cdot C U^{\prime}\left(h^{T I}\right)} .
\end{aligned}
$$

Consider first derivatives with respect to $\Delta$ :

$$
\begin{aligned}
& \frac{\partial \tilde{S}}{\partial \Delta}=C S^{\prime}\left(h^{T I}+\Delta\right)-C S^{\prime}\left(h^{T I}-\delta^{*}(\Delta) / \beta\right) \cdot \delta^{*^{\prime}}(\Delta) \stackrel{\Delta=0}{=} 0, \\
& \frac{\partial \tilde{V}}{\partial \Delta}=C U^{\prime}\left(h^{T I}+\Delta\right)-C U^{\prime}\left(h^{T I}-\delta^{*}(\Delta) / \beta\right) \cdot \delta^{*^{\prime}}(\Delta) \stackrel{\Delta=0}{=} 0 .
\end{aligned}
$$

This shows that a linear approximation does not produce an affirmative answer. Therefore the sign of the second derivatives is decisive:

$$
\begin{aligned}
\frac{\partial^{2} \tilde{S}}{\partial \Delta \partial \Delta} & =C S^{\prime \prime}\left(h^{T I}+\Delta\right)+C S^{\prime \prime}\left(h^{T I}-\delta^{*}(\Delta) / \beta\right) / \beta \cdot\left(\delta^{*^{\prime}}(\Delta)\right)^{2}-C S^{\prime}\left(h^{T I}-\delta^{*}(\Delta) / \beta\right) \cdot \delta^{*^{\prime \prime}}(\Delta) \\
& \stackrel{\Delta=0}{=} C S^{\prime \prime}\left(h^{T I}\right)(1+\beta) / \beta-C S^{\prime}\left(h^{T I}\right) \cdot \delta^{*^{\prime \prime}}(0) \\
& =(1+\beta) / \beta \cdot\left\{C S^{\prime \prime}\left(h^{T I}\right)-C S^{\prime}\left(h^{T I}\right) / 2 \cdot\left[\frac{C S^{\prime \prime}\left(h^{T I}\right)}{C S^{\prime}\left(h^{T I}\right)}+\frac{C U^{\prime \prime}\left(h^{T I}\right)}{C U^{\prime}\left(h^{T I}\right)}\right]\right\} \\
& >(1+\beta) / \beta \cdot\left\{C S^{\prime \prime}\left(h^{T I}\right)-C S^{\prime}\left(h^{T I}\right) / 2 \cdot\left[2 \cdot \frac{C S^{\prime \prime}\left(h^{T I}\right)}{C S^{\prime}\left(h^{T I}\right)}\right]\right\}=0,
\end{aligned}
$$

where the inequality sign follows in Case I from $\left(*^{I}\right)$ and $C S^{\prime}\left(h^{T I}\right)<0$, and in Case II from $\left(*^{I I}\right)$ and $C S^{\prime}\left(h^{T I}\right)>0$. The same calculations for $V$ result in:

$$
\begin{aligned}
\frac{\partial^{2} \tilde{V}}{\partial \Delta \partial \Delta} \stackrel{\Delta=0}{=} C U^{\prime \prime}\left(h^{T I}\right)(1+\beta) / \beta-C U^{\prime}\left(h^{T I}\right) \cdot \delta^{*^{\prime \prime}}(0) \\
=(1+\beta) / \beta \cdot\left\{C U^{\prime \prime}\left(h^{T I}\right)-C U^{\prime}\left(h^{T I}\right) / 2 \cdot\left[\frac{C S^{\prime \prime}\left(h^{T I}\right)}{C S^{\prime}\left(h^{T I}\right)}+\frac{C U^{\prime \prime}\left(h^{T I}\right)}{C U^{\prime}\left(h^{T I}\right)}\right]\right\} \\
>(1+\beta) / \beta \cdot\left\{C U^{\prime \prime}\left(h^{T I}\right)-C U^{\prime}\left(h^{T I}\right) / 2 \cdot\left[2 \cdot \frac{C U^{\prime \prime}\left(h^{T I}\right)}{C U^{\prime}\left(h^{T I}\right)}\right]\right\}=0,
\end{aligned}
$$

where the inequality sign again follows in Case I from $\left(*^{I}\right)$ and $C U^{\prime}\left(h^{T I}\right)>0$, and in Case II from $\left(*^{I I}\right)$ and $C U^{\prime}\left(h^{T I}\right)<0$.

If $C S^{\prime}=0$ and $C S^{\prime \prime}=0$ (and condition $(*)$ is fulfilled), then any (second-order) variation in tax rates, in particular one that increases utility, increases tax revenues. $\|$ problem:

Proof of Theorem 2. For a fixed set of $(h, m)$ pairs $\left\{\left(h_{1}, m_{1}\right), \ldots\left(h_{n}, m_{n}\right)\right\}$, consider the following convexified

$$
\max _{\pi=\left(\pi_{1}, \ldots, \pi_{n}\right)} \sum_{i=1}^{n} \pi_{i} v\left(h_{i}, m_{i}\right)
$$

subject to

$$
\begin{aligned}
& \sum_{i=1}^{n} \pi_{i} \gamma\left(h_{i}, m_{i}\right)=0 \\
& \sum_{i=1}^{n} \pi_{i}=1 \\
& 0 \leq \pi_{i} \leq 1,
\end{aligned}
$$

(C) 2010 The Review of Economic Studies Limited 
where $v\left(h_{t}, m_{t}\right)=u\left(h_{t}-g, h_{t}, m_{t}\right)$ and $\gamma\left(h_{t}, m_{t}\right)=u_{c}\left(h_{t}-g, h_{t}, m_{t}\right) \cdot\left(h_{t}-g-\lambda^{L}\left(h_{t}\right) h_{t}\right)+\lambda^{M}\left(m_{t}\right) m_{t}$.

A $\pi$ is called admissible if it fulfills (41)-(43). It is a standard result in linear programming (see e.g., Dantzig, 1963) that a corner (or vertex or extreme point) solution is optimal, where a corner is defined as follows:

Definition 4. An admissible $\pi=\left\{\pi_{1}, \ldots, \pi_{n}\right\}$ is a corner (or vertex or extreme point) if for all admissible $\tilde{\pi}=\left\{\tilde{\pi}_{1}, \ldots, \tilde{\pi}_{n}\right\}$ and $\hat{\pi}=\left\{\hat{\pi}_{1}, \ldots, \hat{\pi}_{n}\right\}$ and $\lambda \in(0,1)$ :

$$
\pi=\lambda \tilde{\pi}+(1-\lambda) \hat{\pi} \Rightarrow \pi=\tilde{\pi}=\hat{\pi} .
$$

I show next that for a corner $\pi$, at most two $\pi_{i}$ are not zero. Suppose there is a corner $\pi$ with a support larger than 2. Thus there exist three different $i\left(i_{1}, i_{2}, i_{3}\right)$ such that $\pi_{i_{1}}, \pi_{i_{2}}, \pi_{i_{3}} \neq 0$. I now define $\tilde{\pi} \neq \pi$ and $\hat{\pi} \neq \pi$ such that $\frac{1}{2} \tilde{\pi}+\frac{1}{2} \hat{\pi}=\pi$, i.e. $\pi$ is not a corner. Note that without loss of generality all $\gamma_{j}:=\gamma\left(h_{i_{j}}, m_{i_{j}}\right)$ $(j \in\{1,2,3\})$ take different values, since for the same $\gamma$ value, only the $h$ that gives the highest utility is chosen. Define $\tilde{\pi}_{i_{1}}=\pi_{1}-\epsilon \frac{\gamma_{2}-\gamma_{3}}{\gamma_{1}-\gamma_{3}}, \tilde{\pi}_{i_{2}}=\pi_{2}+\epsilon, \tilde{\pi}_{i_{3}}=\pi_{3}-\epsilon \frac{\gamma_{1}-\gamma_{2}}{\gamma_{1}-\gamma_{3}}, \hat{\pi}_{i_{1}}=\pi_{1}+\epsilon \frac{\gamma_{2}-\gamma_{3}}{\gamma_{1}-\gamma_{3}}, \hat{\pi}_{i_{2}}=\pi_{2}-\epsilon, \hat{\pi}_{i_{3}}=\pi_{3}+\epsilon \frac{\gamma_{1}-\gamma_{2}}{\gamma_{1}-\gamma_{3}}$ for some sufficiently small $\epsilon>0$. For all other indices, $\tilde{\pi}, \hat{\pi}$ and $\pi$ coincide. Since $\tilde{\pi}$ and $\hat{\pi}$ are admissible and fulfil $\frac{1}{2} \tilde{\pi}+\frac{1}{2} \hat{\pi}=\pi, \pi$ is not a corner. Thus the solution of the convexified problem has the desired property of a support not larger than 2 .

I now show that this is also the case for the Ramsey problem. Suppose the Ramsey problem implements the $(h, m)$ pairs $\left(h^{1}, m^{1}\right) \ldots\left(h^{n}, m^{n}\right)$, where $\left(h^{i}, m^{i}\right)$ is implemented at dates $I_{i}:=\left\{t \mid\left(h_{t}, m_{t}\right)=\left(h^{i}, m^{i}\right)\right\}$. Define $\pi$ :

$$
\pi_{i}:=(1-\beta) \sum_{t \in I_{i}} \beta^{t}
$$

Since the Ramsey solution fulfills the implementability constraint, $\pi$ is admissible. The above arguments show that an admissible $\tilde{\pi}$ exists with a support not larger than 2 , which produces the same welfare level. This implies that

$$
(1-\beta) \sum_{t=0}^{\infty} \beta^{t} v\left(h_{t}, m_{t}\right)=\sum_{i=1}^{n} \pi_{i} v\left(h^{i}, m^{i}\right) \leq \tilde{\pi}_{1} v\left(h^{i_{1}}, m^{i_{1}}\right)+\tilde{\pi}_{2} v\left(h^{i_{2}}, m^{i_{2}}\right)
$$

for some $1 \leq i_{1}, i_{2} \leq n$.

I now show that $J_{1}, J_{2} \subset \mathbb{N}_{0}$ exist, such that $J_{1} \cup J_{2}=\mathbb{N}_{0}$ and

$$
\begin{aligned}
& (1-\beta) \sum_{s \in J_{1}} \beta^{s}=\tilde{\pi}_{1} \quad \text { and } \\
& (1-\beta) \sum_{s \in J_{2}} \beta^{s}=\tilde{\pi}_{2} .
\end{aligned}
$$

The following algorithm achieves this. Define a sequence of index sets $J_{1}(t), J_{2}(t)$ as follows: $J_{1}(-1)=J_{2}(-1)=\emptyset$.

$$
\begin{array}{ll}
J_{1}(t)=J_{1}(t-1) \cup\{t\}, J_{2}(t)=J_{2}(t-1), & \text { if } \tilde{\pi}_{1}-\hat{\pi}_{1}(t-1) \geq \tilde{\pi}_{2}-\hat{\pi}_{1}(t-1) \\
J_{1}(t)=J_{1}(t-1), J_{2}(t)=J_{2}(t-1) \cup\{t\}, & \text { otherwise, }
\end{array}
$$

where $\hat{\pi}_{i}(t):=(1-\beta) \sum_{s \in J_{i}(t)} \beta^{s}$ and $\hat{\pi}_{i}(-1)=0$.

$J_{1}:=\lim _{t \rightarrow \infty} J_{1}(t)$ and $J_{2}:=\lim _{t \rightarrow \infty} J_{2}(t)$.

This algorithm works if $\tilde{\pi}_{i} \geq \hat{\pi}_{i}(t)$ holds for all $t \geq 0$. This is true for $t$ if it is true for $t-1$ and if

$$
(1-\beta) \beta^{t} \leq \max \left\{\tilde{\pi}_{1}-\hat{\pi}_{1}(t-1), \tilde{\pi}_{2}-\hat{\pi}_{2}(t-1)\right\} .
$$

Since $\tilde{\pi}_{1}+\tilde{\pi}_{2}=1, \hat{\pi}_{1}(t-1)+\hat{\pi}_{2}(t-1)=(1-\beta) \sum_{s=0}^{t-1} \beta^{s}=1-\beta^{t}$ and thus since $\beta>1 / 2$

$$
\tilde{\pi}_{1}+\tilde{\pi}_{2}-\hat{\pi}_{1}(t-1)-\hat{\pi}_{2}(t-1)=\beta^{t}>2(1-\beta) \beta^{t} .
$$

The algorithm converges because (50) implies (49) and $\hat{\pi}_{i}(t) \rightarrow \tilde{\pi}_{i}$. Thus the same welfare level can be reached with two different tax levels:

$$
\begin{aligned}
(1-\beta) \sum_{t=0}^{\infty} \beta^{t} v\left(h_{t}, m_{t}\right) & =\sum_{i=1}^{n} \pi_{i} v\left(h^{i}, m^{i}\right) \\
& \leq \tilde{\pi}_{1} v\left(h^{i_{1}}, m^{i_{1}}\right)+\tilde{\pi}_{2} v\left(h^{i_{2}}, m^{i_{2}}\right)=(1-\beta)\left(\sum_{s \in J_{1}} \beta^{s} v\left(h^{i_{1}}, m^{i_{1}}\right)+\sum_{s \in J_{2}} \beta^{s} v\left(h^{i_{2}}, m^{i_{2}}\right)\right) .
\end{aligned}
$$


An infinite support can be ruled out as follows. Consider the problem truncated at time $n$. The support of these problems is not larger than 2. Since the welfare of the solution for $n=\infty$ is the limit for $n \rightarrow \infty$, the optimal solution can always be approximated by a solution with a finite support (of size 2).

Proof of Theorem 3. The Ramsey problem is to choose $c_{t}$ and $h_{t}$ to maximize utility subject to implementability and resource constraints. In a first step it is shown that both these constraints can be written as inequalities, such that the (relaxed) Ramsey problem reads as follows:

$$
\begin{aligned}
\operatorname{Max}_{c_{t}, h_{t}} & \sum_{t=0}^{\infty} \beta^{t}\left(w\left(c_{t}\right)-\chi\left(h_{t}\right)\right) \\
\text { s.t. } & \sum_{t \geq 0} \beta^{t}\left(w_{c}\left(c_{t}\right) \cdot c_{t}-\chi_{h}\left(h_{t}\right) \cdot h_{t}\right) \geq 0 \\
& c_{t}+g \leq h_{t} .
\end{aligned}
$$

Suppose first that in the (relaxed) maximization problem the resource constraint is fulfilled with strict inequality for some $t$. Then decreasing $h_{t}$ improves welfare and still satisfies the relaxed implementability constraint (the implementability constraint is decreasing in $h_{t}$ ).

Thus the resource constraint is fulfilled with equality for all $t$, and $c_{t}=h_{t}-g$.

Suppose now that the implementability constraint is fulfilled with strict inequality. Then for some $t$ :

$$
\left(w_{c}\left(c_{t}\right) \cdot c_{t}-\chi_{h}\left(h_{t}\right) \cdot h_{t}\right)>0 .
$$

Since $c_{t}+g=h_{t}$ :

$$
\begin{aligned}
0 & <\left(w_{c}\left(c_{t}\right) \cdot c_{t}-\chi_{h}\left(h_{t}\right) \cdot h_{t}\right) \\
& =w_{c}\left(c_{t}\right) \cdot\left(h_{t} \cdot\left(1-\chi_{h}\left(h_{t}\right) / w_{c}\left(c_{t}\right)\right)-g\right) \\
& \Rightarrow\left(1-\chi_{h}\left(h_{t}\right) / w_{c}\left(c_{t}\right)\right)>0 \\
& \Leftrightarrow w_{c}\left(c_{t}\right)>\chi_{h}\left(h_{t}\right) .
\end{aligned}
$$

Thus increasing $h_{t}$ and $c_{t}$ by the same (small) amount improves welfare. The relaxed implementability constraint is still fulfilled since it was assumed to hold with strict inequality.

These arguments imply that the solution to the relaxed problem fulfills both constraints with equality. Therefore the solution to the relaxed problem and the solution to the Ramsey problem coincide.

A substitution of variables $v_{t}:=w\left(c_{t}\right)$ results in an equivalent maximization problem $\left(P^{*}\right)$ which reads as follows:

$$
\begin{aligned}
\operatorname{Max}_{v_{t}, h_{t}} & \sum_{t=0}^{\infty} \beta^{t}\left(v_{t}-\chi\left(h_{t}\right)\right) \\
\text { s.t. } & \sum_{t \geq 0} \beta^{t}\left(\varphi\left(\psi\left(v_{t}\right)\right)-\chi_{h}\left(h_{t}\right) \cdot h_{t}\right) \geq 0 \\
& \psi\left(v_{t}\right)+g \leq h_{t}
\end{aligned}
$$

for all feasible $v_{t}$ (those where a $c_{t}$ exists such that $v_{t}=u\left(c_{t}\right), \psi(v)=w^{-1}(v)$ and $\varphi(c)=w_{c}(c) \cdot c$.

It will be shown that this problem is convex for IRRA utility functions. This amounts to showing that both constraints are convex. This is true for the resource constraint, since the inverse of any increasing concave utility function is convex. For the implementability constraint, $\kappa(v):=\varphi\left(\psi\left(v_{t}\right)\right)$ has to be a concave function (concave since the inequality sign is $\geq$ and not $\leq$.). $\chi_{h}\left(h_{t}\right) \cdot h_{t}$ is a convex function by assumption, so that

$$
\begin{aligned}
\kappa^{\prime \prime}(v) & =\varphi^{\prime \prime}\left(\psi^{\prime}\right)^{2}+\varphi^{\prime} \psi^{\prime \prime} \\
& =\frac{2 w^{\prime \prime}+w^{\prime \prime \prime} \cdot c}{\left(w^{\prime}\right)^{2}}-\frac{\left(w^{\prime}+w^{\prime \prime} c\right) w^{\prime \prime}}{\left(w^{\prime}\right)^{3}} \\
& =\frac{w^{\prime \prime}}{\left(w^{\prime}\right)^{2}}\left(1+\frac{w^{\prime \prime \prime} c}{w^{\prime \prime}}-\frac{w^{\prime \prime} c}{w^{\prime}}\right) \leq 0
\end{aligned}
$$

since $w$ is increasing and concave and IRRA is equivalent to

$$
1+\frac{w^{\prime \prime \prime} c}{w^{\prime \prime}}-\frac{w^{\prime \prime} c}{w^{\prime}} \geq 0
$$


Since problem $\left(P^{*}\right)$ is strictly concave, first-order conditions for every $t$ have a unique solution $\left(v_{t}^{*}, h_{t}^{*}\right)$. Since firstorder conditions are necessary for an optimum, $\left(v_{t}^{*}, h_{t}^{*}\right)$ is the optimal choice at $t$. Furthermore, since the maximization problem is identical for all $t$, the same $\left(v^{*}, h^{*}\right)$ is implemented in every period $t$. As problem $\left(P^{*}\right)$ is equivalent to the Ramsey problem, $\left(c^{*}:=w^{-1}\left(v^{*}\right), h^{*}\right)$ is the optimal choice in every period. \|

Proof of Theorems 4, 5 and 6. Follow from Theorem 7.

Proof of Theorem 7. It holds that

$$
\begin{aligned}
C U^{\prime} & =\mu-\chi \\
C U^{\prime \prime} & =\mu^{\prime}-\chi^{\prime} \\
C S^{\prime} & =\mu^{\prime} c+\mu c^{\prime}-\omega^{\prime} \chi h-\omega \chi^{\prime} h-\omega \chi \\
C S^{\prime \prime} & =2 \mu^{\prime} c^{\prime}+\mu^{\prime \prime} c+\mu c^{\prime \prime}-\omega^{\prime \prime} \chi h-\omega^{\prime} \chi^{\prime} h-\omega^{\prime} \chi-\omega^{\prime} \chi^{\prime} h-\omega \chi^{\prime \prime} h-2 \omega \chi^{\prime}-\omega^{\prime} \chi .
\end{aligned}
$$

Define the consumption output ratio as $1-\tilde{\tau}=\frac{c}{h}$, which equals $\frac{\omega \chi}{\mu}$ since $C S=0$. It then holds that

$$
\begin{aligned}
\frac{C S^{\prime}}{C U^{\prime}} & =\frac{\mu^{\prime} c+\mu c^{\prime}-\omega^{\prime} \chi h-\omega \chi^{\prime} h-\omega \chi}{\mu-\chi} \\
& =\frac{(1-\tilde{\tau}) \epsilon_{\mu}+c^{\prime}-\epsilon_{\omega}(1-\tilde{\tau})-\epsilon_{\chi}(1-\tilde{\tau})-(1-\tilde{\tau})}{1-\frac{\chi}{\mu}} \\
& =\frac{1-\tilde{\tau}}{\Delta}\left(\epsilon_{\mu}-1+\epsilon_{c}-\epsilon_{\omega}-\epsilon_{\chi}\right)
\end{aligned}
$$

since

$$
\begin{gathered}
\frac{\chi^{\prime}}{\mu^{\prime}}=\frac{\epsilon_{\chi}}{\epsilon_{\mu}}(1-\Delta) \\
\frac{C S^{\prime \prime}}{C U^{\prime \prime}}=\frac{\mu^{\prime \prime} c+\mu^{\prime} c^{\prime}+\mu^{\prime} c^{\prime}+\mu c^{\prime \prime}-\omega^{\prime \prime} \chi h-2 \omega^{\prime} \chi^{\prime} h-2 \omega^{\prime} \chi-\omega^{\prime} \chi^{\prime} h-\omega \chi^{\prime \prime} h-2 \omega \chi^{\prime}}{\mu^{\prime}-\chi^{\prime}} \\
=\frac{(1-\tilde{\tau})\left\{\epsilon_{\mu^{\prime}}+\epsilon_{c}\left(2+\frac{\epsilon_{c^{\prime}}}{\epsilon_{\mu}}\right)-\frac{\epsilon_{\omega^{\prime}} \epsilon \omega}{\epsilon \mu}-2 \frac{\epsilon_{\omega} \epsilon}{\epsilon \mu}-2 \frac{\epsilon_{\omega}}{\epsilon_{\mu}}-\frac{\epsilon_{\chi^{\prime}} \epsilon_{\chi}}{\epsilon_{\mu}}-2 \frac{\epsilon \chi}{\epsilon \mu}\right\}}{1-\frac{\epsilon_{\chi}}{\epsilon_{\mu}}(1-\Delta)} \\
=(1-\tilde{\tau}) \frac{\epsilon_{\mu^{\prime}} \epsilon_{\mu}+\epsilon_{c}\left(2 \epsilon_{\mu}+\epsilon_{c^{\prime}}\right)-\epsilon_{\omega^{\prime}} \epsilon_{\omega}-2 \epsilon_{\omega} \epsilon_{\chi}-2 \epsilon_{\omega}-\epsilon_{\chi^{\prime}} \epsilon_{\chi}-2 \epsilon_{\chi}}{\epsilon_{\mu}-\epsilon_{\chi}(1-\Delta)} .
\end{gathered}
$$

Dividing by $(1-\tilde{\tau})$ shows that the criterion $\frac{C S^{\prime \prime}}{C U^{\prime \prime}}-\frac{C S^{\prime}}{C U^{\prime}}<0$ equals $\left(*^{L}\right)$. $\|$

Proof of Proposition 2. The household's present value budget constraint reads as follows:

$$
B_{-1}=\sum_{t \geq 0} q_{t} \cdot\left\{c_{t}-I_{t} \cdot E_{t}\right\}
$$

From the free-entry condition $k=\frac{m\left(1, v_{t}\right)}{v_{t}} \frac{1}{2}\left(1-\frac{b}{1-\tau_{t}}\right)$, it follows that

$$
\left(1-\tau_{t}\right)=\frac{\frac{b}{2} m\left(1, v_{t}\right) / v_{t}}{\frac{1}{2} m\left(1, v_{t}\right) / v_{t}-\kappa} .
$$

Income then equals

$$
\begin{aligned}
I_{t} & =\frac{1}{2}\left(1-\tau_{t}\right)+\frac{1}{2} b \\
& =\frac{1}{2} \frac{\frac{b}{2} m\left(1, v_{t}\right) / v_{t}}{\frac{1}{2} m\left(1, v_{t}\right) / v_{t}-\kappa}+\frac{1}{2} b \\
& =\frac{b}{2}\left\{1+\frac{\frac{1}{2} m\left(1, v_{t}\right) / v_{t}}{\frac{1}{2} m\left(1, v_{t}\right) / v_{t}-\kappa}\right\} \\
& =\frac{b}{2}\left\{\frac{m\left(1, v_{t}\right) / v_{t}-\kappa}{\frac{1}{2} m\left(1, v_{t}\right) / v_{t}-\kappa}\right\} .
\end{aligned}
$$


The proposition follows since the consumption Euler equation implies that $q_{t}=\beta^{t} \cdot \frac{u_{c}(t)}{u_{c}(0)}$ and $E_{t}=m\left(1, v_{t}\right) . \|$

Proof of Theorem 8. It holds that

$$
\begin{aligned}
C U^{\prime} & =\mu \\
C U^{\prime \prime} & =\mu^{\prime} \\
C S^{\prime} & =\omega^{\prime} \mu m+\omega \mu^{\prime} m+\omega \mu \\
C S^{\prime \prime} & =\omega^{\prime \prime} \mu m+2 \omega^{\prime} \mu^{\prime} m+\omega \mu^{\prime \prime} m+2 \omega^{\prime} \mu+2 \omega \mu^{\prime} .
\end{aligned}
$$

It then follows that

$$
\begin{aligned}
\frac{C S^{\prime}}{C U^{\prime}} & =\frac{\omega^{\prime} \mu m+\omega \mu^{\prime} m+\omega \mu}{\mu} \\
& =\omega^{\prime} m+\omega \frac{\mu^{\prime} m}{\mu}+\omega \\
& =\omega\left(\epsilon_{\omega}+\epsilon_{\mu}+1\right)
\end{aligned}
$$

and

$$
\begin{aligned}
\frac{C S^{\prime \prime}}{C U^{\prime \prime}} & =\frac{\omega^{\prime \prime} \mu m+2 \omega^{\prime} \mu^{\prime} m+\omega \mu^{\prime \prime} m+2 \omega^{\prime} \mu+2 \omega \mu^{\prime}}{\mu^{\prime}} \\
& =\omega\left(\frac{\epsilon_{\omega^{\prime}} \epsilon_{\omega}}{\epsilon_{\mu}}+2 \epsilon_{\omega}\left(1+\frac{1}{\epsilon_{\mu}}\right)+2+\epsilon_{\mu^{\prime}}\right) .
\end{aligned}
$$

Dividing by $\omega$ shows that the criterion $\frac{C S^{\prime \prime}}{C U^{\prime \prime}}-\frac{C S^{\prime}}{C U^{\prime}}<0$ equals $\left(*^{M}\right)$.

Acknowledgements. I would like to thank the editor, three anonymous referees, and Dirk Krüger, Stefan Niemann, Fabrizio Zilibotti, and the seminar participants at the University of Pennsylvania for helpful comments and suggestions that have been incorporated throughout the paper. Support from the National Centre of Competence in Research "Financial Valuation and Risk Management" (NCCR FINRISK) and the Research Priority Program on Finance and Financial Markets of the University of Zurich is gratefully acknowledged.

\section{REFERENCES}

AIYAGARI, R. S. (1994), “Optimal Capital Income Taxation with Incomplete Markets, Borrowing Constraints, and Constant Discounting" (Working Paper No. 508, Federal Reserve Bank of Minneapolis).

ARUOBA, B. and CHUGH, S. (2006), "Optimal Fiscal and Monetary Policy When Money is Essential" (Mimeo, University of Maryland).

BARBIE, M., HAGEDORN, M. and KAUL, A. (2009), "Optimal Redistributive Cycles" (Mimeo, University of Zurich).

BARRO, R. J. (1979), "On the Determination of the Public Debt", Journal of Political Economy, 87, 940-971.

CHAMLEY, C. (1986), "Optimal Taxation of Capital Income in General Equilibrium with Infinite Lives", Econometrica, 54 (3), 607-622.

CHARI, V. V. and KEHOE, P. (1999), "Optimal Fiscal and Monetary Policy”, in Taylor, J. and Woodford, M. (eds.) Handbook of Macroeconomics, vol. 1 (Amsterdam: North-Holland).

CHARI, V. V., KEHOE, P. and MCGRATTAN, E. (2002), "Can Sticky Price Models Generate Volatile and Persistent Real Exchange Rates?” Review of Economic Studies, 69, 533-563.

CHARI, V. V., KEHOE, P. and MCGRATTAN, E. (2007), "Business Cycle Accounting", Econometrica, 75, $781-836$.

GALI, J., GERTLER, M. and LOPEZ-SALIDO, J. (2003), "Markups, Gaps, and the Welfare Costs of Business Fluctuations" (NBER Working Paper W8850).

GOLLIER, C. (2001), The Economics of Risk and Time (Cambridge: MIT Press).

HAGEDORN, M. and MANOVSKII, I. (2008), "The Cyclical Behavior of Equilibrium Unemployment and Vacancies Revisited", American Economic Review, 98 (4), 1692-1706.

HALL, R. E. and MILGROM, P. R. (2008), "The Limited Influence of Unemployment on the Wage Bargain", American Economic Review, 98 (4), 1653-1674.

HANSEN, G. (1985), "Indivisible Labour and the Business Cycle”, Journal of Monetary Economics, 16, 309-327.

(C) 2010 The Review of Economic Studies Limited 
HASSLER, J., KRUSELL, P., STORESLETTEN, K. and ZILIBOTTI, F. (2008), "On the Optimal Timing of Capital Taxes", Journal of Monetary Economics, 55 (4), 692-709.

HUNGERBÜHLER, M., LEHMANN, E., PARMENTIER, A. and VAN DER LINDEN, B. (2006), "Optimal Redistributive Taxation in a Search Equilibrium Model", Review of Economic Studies, 73 (3), $743-767$.

JUDD, K. (1985), "Redistributive Taxation in a Simple Perfect Foresight Model", Journal of Public Economics, 28 (1), 59-83.

LAGOS, R. (2005), “Asset Prices and Liquidity in an Exchange Economy” (Mimeo, New York University).

LAGOS, R. and WRIGHT, R. (2005), "A Unified Framework for Monetary Theory and Policy Analysis", Journal of Political Economy, 113 (3), 463-484.

LUCAS, R. E. J. (1987), Models of Business Cycles (New York: Basil Blackwell).

LUCAS, R. E. J. and STOKEY, N. L. (1983), "Optimal Fiscal and Monetary Policy in an Economy without Capital", Journal of Monetary Economics, 12 (1), 55-93.

MCGRATTAN, E., ROGERSON, R. and WRIGHT, R. (1997), "An Equilibrium Model of the Business Cycle with Household Production and Fiscal Policy", International Economic Review, 38 (2), 267-290.

MIRRLEES, J. (1971), "An Exploration in the Theory of Optimal Income Taxation", Review of Economic Studies, 38, 175-208.

OGAKI, M. and ZHANG, Q. (2001), "Decreasing Relative Risk Aversion and Tests of Risk Sharing”, Econometrica, 69 (2), 515-526.

PISSARIDES, C. (1985), "Short-run Equilibrium Dynamics of Unemployment, Vacancies and Real Wages", American Economic Review, 75, 676-690.

PISSARIDES, C. (2000), Equilibrium Unemployment Theory (Cambridge: MIT Press).

PRESCOTT, E. C. (2004), "Why do Americans Work so Much More than Europeans", Federal Reserve Bank of Minneapolis Quarterly Review, 28 (1), 2-13.

SHIMER, R. (2005), "The Cyclical Behavior of Equilibrium Unemployment and Vacancies", American Economic Review, 95 (1), 25-49.

VISSING-JORGENSON, A. (2002), "Limited Asset Market Participation and the Elasticity of Intertemporal Substitution", Journal of Political Economy, 110, 825-853. 